\title{
A wide-ranging Pseudomonas aeruginosa PeptideAtlas build: A useful proteomic resource for a versatile pathogen
}

\author{
J.A. Reales-Calderón ${ }^{\mathrm{a}}$, Z. Sun ${ }^{\mathrm{b}}$, V. Mascaraque ${ }^{\mathrm{a}}$, E. Pérez-Navarro ${ }^{\mathrm{c}}$, V. Vialás $^{\mathrm{a}}$, E.W. Deutsch ${ }^{\mathrm{b}}$, \\ R.L. Moritz ${ }^{\mathrm{b}}$, C. Gil ${ }^{\mathrm{a}, \mathrm{c}}$, J.L. Martínez ${ }^{\mathrm{d}}$, G. Molero ${ }^{\mathrm{a}, *}$ \\ a Departamento de Microbiología y Parasitología, Facultad de Farmacia, Universidad Complutense de Madrid, Spain \\ ${ }^{\mathrm{b}}$ Institute for Systems Biology, Seattle, WA, USA \\ ${ }^{\mathrm{c}}$ Unidad de Proteómica de la Universidad Complutense de Madrid, Spain \\ d Departamento de Biotecnología Microbiana, Centro Nacional de Biotecnología, CSIC, Madrid, Spain
}

\section{A R T I C L E I N F O}

\section{Keywords:}

Pseudomonas

Bacterial PeptideAtlas

Pathogen

Database

Proteomics

Tool for targeted proteomic studies

\begin{abstract}
A B S T R A C T
Pseudomonas aeruginosa is an important opportunistic human pathogen with high prevalence in nosocomial infections. This microorganism is a good model for understanding biological processes such as the quorum-sensing response, the metabolic integration of virulence, the mechanisms of global regulation of bacterial physiology, and the evolution of antibiotic resistance. Till now, $P$. aeruginosa proteomic data, although available in several on-line repositories, were dispersed and difficult to access. In the present work, proteomes of the PAO1 strain grown under different conditions and from diverse cellular compartments have been joined to build the Pseudomonas PeptideAtlas. This resource is a comprehensive mass spectrometry-derived peptide and inferred protein database with $71.3 \%$ coverage of the total predicted proteome of $P$. aeruginosa PAO1, the highest coverage among bacterial PeptideAtlas datasets. The proteins included cover $89 \%$ of metabolic proteins, $72 \%$ of proteins involved in genetic information processing, $83 \%$ of proteins responsible for environmental information processing, more than $88 \%$ of the ones related to quorum sensing and biofilm formation, and $89 \%$ of proteins responsible for antimicrobial resistance. It exemplifies a necessary tool for targeted proteomics studies, systemwide observations, and cross-species observational studies. The manuscript describes the building of the PeptideAtlas and the contribution of the different proteomic data used.

Significance: Pseudomonas aeruginosa is among the most versatile human bacterial pathogens. Studies of its proteome are very important as they can reveal virulence factors and mechanisms of antibiotic resistance. The construction of a proteomic resource such as the PeptideAtlas enables targeted proteomics studies, system-wide observations, and cross-species observational studies.
\end{abstract}

\section{Introduction}

Pseudomonas aeruginosa is an important opportunistic pathogen with high prevalence in nosocomial infections [1,2]. In addition, this bacterial pathogen is the major cause of chronic infections in patients suffering obstructive pulmonary disease and cystic fibrosis (CF) [3-5]. It is able to survive, persist in, and colonize diverse environments [6], including soil and water. The phylogenetic analysis of clinical and environmental isolates of this organism show that the population is panmictic. There are no differentiated clinical and environmental lineages, and the success of infection relies more on the underlying situation of the patient than on the specific characteristics of a given clone that may have evolved towards virulence [7-9]. Differing from other more specific pathogens that have become virulent through the acquisition of genetic material [10], the virulence determinants of $P$. aeruginosa belong to the core genome of this microorganism [11]: they are present in all members of the species and have not been acquired by a specific lineage evolved to be infectious. Using similar mechanisms, $P$. aeruginosa is able to infect a large variety of hosts, including amoebae, plants, worms, insects, and mammals [12]. As a highly versatile species, $P$. aeruginosa grows under aerobic and anaerobic conditions, over a wide temperature range, and can make use of several carbon sources [13]. Further, it presents a large repertoire of virulence determinants [13,14]. The expression of several of them is regulated through a complex quorum-

\footnotetext{
* Corresponding author.

E-mail address: gloriamolero@ucm.es (G. Molero).
} 


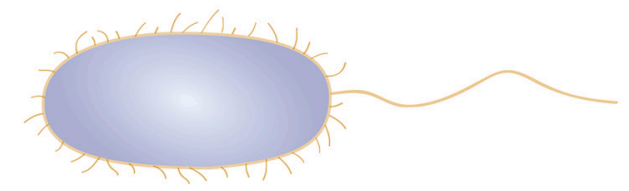

Subcellular fractionation
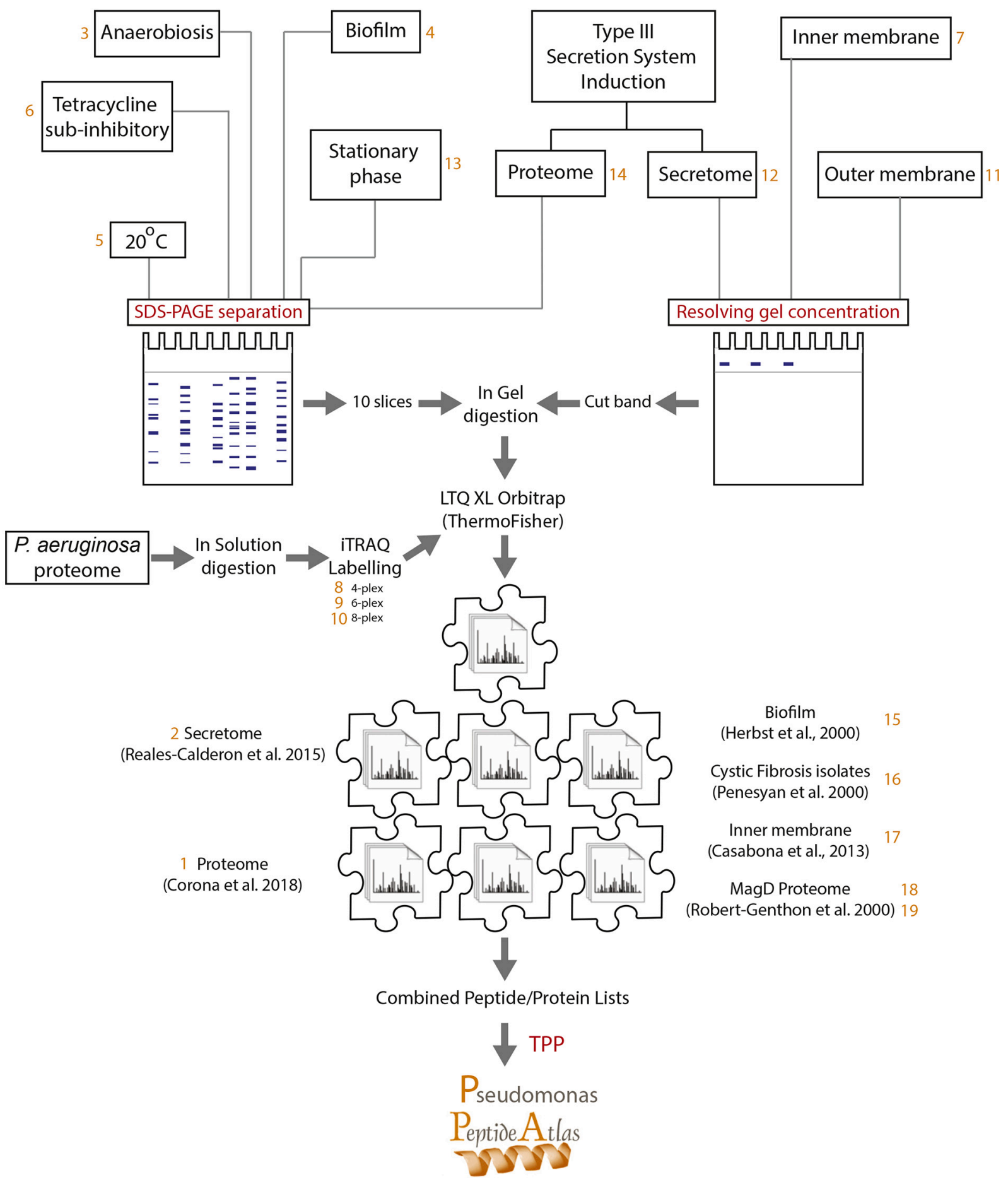

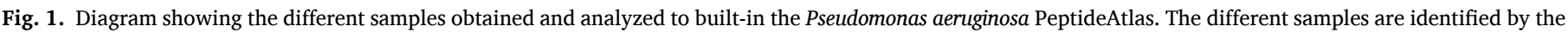

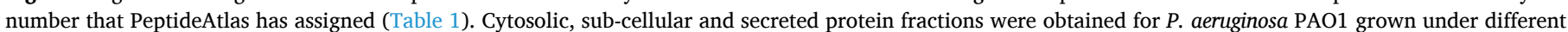

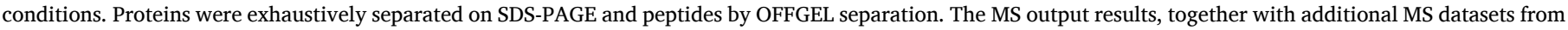
other authors were all processed with the TPP tool suite. 
Table 1

Pseudomonas aeruginosa proteomic samples included in this work.

\begin{tabular}{|c|c|c|c|c|c|c|c|}
\hline Sample number & Database name & Proteomic analysis & Runs & Number of identified proteins & Unique proteins & Reference & Repositories* \\
\hline 1 & pao1_fcp001_proteome_4plex & iTRAQ/ LC-MS/MS & 30 & 2762 & 51 & [41] & PASS00809 \\
\hline 2 & pao1_vescl_secretome_4plex & iTRAQ/ LC-MS/MS & 12 & 1265 & 12 & [24] & PASS00808 \\
\hline 3 & pao1_anaerobiosis & LC-MS/MS & 5 & 2252 & 20 & & PASS00804 \\
\hline 4 & pao1_biofilm & LC-MS/MS & 5 & 1689 & 15 & & PASS00803 \\
\hline 5 & pao1_growth_20c & LC-MS/MS & 5 & 2313 & 6 & & PASS00800 \\
\hline 6 & pao1_growth_TCN & LC-MS/MS & 5 & 2465 & 13 & & PASS00801 \\
\hline 7 & pao1_inner_memb & LC-MS/MS & 5 & 1158 & 3 & & PASS00805 \\
\hline 8 & pao1_itraq_4plex & iTRAQ/ LC-MS/MS & 2 & 1568 & 3 & & PASS00821 \\
\hline 9 & pao1_itraq_6plex & iTRAQ/ LC-MS/MS & 2 & 1582 & 2 & & PASS00822 \\
\hline 10 & pao1_itraq_8plex & iTRAQ/ LC-MS/MS & 2 & 1413 & 2 & & PASS00823 \\
\hline 11 & pao1_outer_memb & LC-MS/MS & 1 & 1080 & 4 & & PASS00806 \\
\hline 12 & pao1_secretome_T3SS & LC-MS/MS & 1 & 473 & 4 & & PASS00807 \\
\hline 13 & pao1_stat_phase & LC-MS/MS & 5 & 2504 & 18 & & PASS00799 \\
\hline 14 & pao1_T3SS_induction & LC-MS/MS & 1 & 2486 & 11 & & PASS00802 \\
\hline 15 & PAO1_Fap & LC-MS/MS & 288 & 3698 & 240 & [43] & $\underline{\text { PXD001373 }}$ \\
\hline 16 & Pseudomonas_Cystic_Fibrosis & DIA LC-MS/MS & 80 & 1787 & 223 & [44] & $\overline{\text { PXD002865 }}$ \\
\hline 17 & PAO1_Inner_Membrane_Proteome & LC-MS/MS & 6 & 1656 & 18 & [45] & $\overline{\mathrm{PXD} 000107}$ \\
\hline 18 & PAO1_MagD-WT & LC-MS/MS & 2 & 1102 & 4 & [46] & $\overline{\text { PXD000189 }}$ \\
\hline 19 & PAO1_delta-MagD & LC-MS/MS & 2 & 446 & 0 & [46] & $\overline{\text { PXD000189 }}$ \\
\hline
\end{tabular}

* Datasets available in PeptideAtlas Database (accession code PASS_) and PRIDE Database (accession code PXD_).

sensing network $[15,16]$, as well as a battery of secreted virulence factors (including toxins, siderophores and proteases) and vesicle-engulfed compounds [17-19]. One of the main problems in treating $P$. aeruginosa infections is the low susceptibility to antibiotics of this microorganism, being classified by WHO in the ESKAPE group of pathogens with higher risk of antibiotic resistance [14,20]. This is due to the presence in its genome of genes encoding beta-lactamases and several multidrug efflux pumps [21], among other elements [22]. In addition, P. aeruginosa can evolve to acquire increasing levels of resistance through mutations or through the acquisition of antibiotic resistance genes via horizontal gene transfer, allowing the dissemination of multidrug resistant strains causing nosocomial infections worldwide [23].

The versatility of $P$. aeruginosa is supported by its large genome, ranging between 5 and $7 \mathrm{Mbp}$ in different strains [6], together with a large number of regulatory elements (both transcriptional and posttranscriptional) that allow the organism to adapt its physiology when confronted with different physicochemical conditions and cues specific to each of the habitats it can colonize. All these features make this microorganism, in addition to an important pathogen, a good model for understanding several biological processes, including the quorumsensing response $[15,16]$, the metabolic integration of virulence [24,25], the mechanisms of global regulation of bacterial physiology [26,27], and the evolution of antibiotic resistance [28-34], among others. For this reason, it has been proposed that $P$. aeruginosa should be considered a "lab rat", similar to other model bacteria such as Escherichia coli and Bacillus subtilis [13].

The integrated analysis of $P$. aeruginosa under a systems biology umbrella requires the use of multi-omic techniques, and accurate databases are fundamental to this purpose. Among them, the on-line resource at the Pseudomonas Genomic Database (www.pseudomonas. com) [35] provides updated and well-curated information on the different sequenced strains of this microorganism at the genomic level, while PAMDB, http://pseudomonas.umaryland.edu [36] includes metabolomic information. Post-transcriptional regulation plays a major role in the adaptation of this microorganism to its different habitats [37]. Besides, the identification of factors that are secreted to the extracellular milieu or in extracellular vesicles (EVs) is fundamental to a full understanding of the virulence of this pathogen. In consequence, proteomic studies are needed for a comprehensive analysis of $P$. aeruginosa physiology. However, proteomic data, although available in several on-line repositories, are dispersed and difficult to access. Thus, resources like PeptideAtlas, which compiles the available LC-MS/MSbased shotgun proteomics data, are necessary for targeted proteomics studies, system-wide observations, and cross-species observational studies [38]. To date, 43 PeptideAtlas builds are available, but only 8 of them are from bacteria (http://www.peptideatlas.org/builds/).

Here we present the $P$. aeruginosa PeptideAtlas. To build it, proteomes of $P$. aeruginosa strain PAO1 grown under very different conditions and from diverse cellular compartments have been obtained, analyzed, and joined with data from other authors, one of them including proteomes from clinical strains. The resulting on-line resource is a comprehensive mass spectrometry-derived peptide and inferred protein database with high coverage of the total predicted proteome from this bacterium.

\section{Materials and methods}

\subsection{Bacterial strains and growth conditions}

The $P$. aeruginosa strain used by our group to develop the Pseudomonas PeptideAtlas was the widely used wild-type PAO1. All the growth conditions employed to generate new proteomes used to build the PeptideAtlas are represented in Fig. 1 and Table 1, together with other additional datasets from our group and others deposited in PRIDE [39].

For most of the samples prepared for the present work, PAO1 was grown until exponential phase of growth $\left(\mathrm{OD}_{600}\right.$ of 0.6$)$ in LB Luria Bertani (LB) broth (10 g Peptone, $5 \mathrm{~g}$ Yeast Extract, $5 \mathrm{~g}$ Sodium Chloride) at $37^{\circ} \mathrm{C}$. There were some exceptions: sample 4, biofilm formed in p24 plates at $37^{\circ} \mathrm{C}$ during $48 \mathrm{~h}$; sample 5 , at $20^{\circ} \mathrm{C}$; sample 6, in LB agar; and sample 13 , until $\mathrm{OD}_{600}$ of 4 to reach stationary phase of growth. Also, additives were used for the following samples: for samples 12 and 14, 5 mM EGTA and $20 \mathrm{mM} \mathrm{MgCl}_{2}$ for stimulating Type III secretion [40] during $4 \mathrm{~h}$; and for sample 6 , Tetracycline sub-inhibitory concentration (0.5 mg/l) during $4 \mathrm{~h}$.

All the samples were grown under aerobic conditions except for sample 3, where anaerobiosis was achieved in LB agar plates placed in a generator for GENbox jar 2.51 anaerobic environment (GENbox anaer, Biomerieux) during $48 \mathrm{~h}$ at $37^{\circ} \mathrm{C}$.

All the samples were total extracts (cytosolic proteins mainly) except for samples 7 and 11, where subcellular fractionations were needed to enrich in inner and outer membranes, and the secretome obtained for sample 12.

\subsection{Protein extraction and digestion}

Pellets from $P$. aeruginosa PAO1 cells grown under the different 
conditions were washed and resuspended in $1 \mathrm{ml}$ of PBS supplemented with 1/1000 Protease Inhibitor Cocktail (Complete, Mini, EDTA-free Protease Inhibitor Cocktail Tablets). PAO1 biofilm was washed with PBS and cells were collected to protein extraction. Cells from the different samples were lysed by sonication (Labsonic U) for 3 times, 1 $\mathrm{min}$ each, and centrifuged for $20 \mathrm{~min}$ at $6000 \mathrm{~g}$ at $4^{\circ} \mathrm{C}$. Cell debris was removed by centrifugation $\left(14,000 \mathrm{~g}, 10 \mathrm{~min}, 4^{\circ} \mathrm{C}\right)$. Proteins were frozen at $-80^{\circ} \mathrm{C}$ until used. Protein concentration was measured using Bradford assay (Biorad).

The secretome from the T3SS-induction sample was collected by centrifugation at $7000 \mathrm{~g}$ for $10 \mathrm{~min}$ at $4{ }^{\circ} \mathrm{C}$ and supernatants were filtered through a $0.2 \mu \mathrm{m}$ pore size Nalgene Disposable Filter Unit (Thermo Fisher Scientific) to remove the remaining cells. Proteins were precipitated with methanol/chloroform. The pellet was washed 2 times with PBS and resuspended in $0.5 \mathrm{M}$ Triethylammonium bicarbonate (TEAB) supplemented with 1/1000 Protease Inhibitor Cocktail.

In the case of the inner and outer membranes enriched fractions, cells were pelleted and washed with PBS and resuspended in $1.5 \mathrm{ml}$ of $20 \mathrm{mM}$ HEPES pH 8.0. Then, lysis was reached by sonication for 3 times, $1 \mathrm{~min}$ each, and centrifuged for $20 \mathrm{~min}$ at $6000 \mathrm{~g}$ at $4{ }^{\circ} \mathrm{C}$. After this, supernatant was collected and ultracentrifuged at $100,000 \mathrm{~g}$ during $1 \mathrm{~h}$ at $4{ }^{\circ} \mathrm{C}$. Then, supernatant was collected, and pellet was resuspended in $1.5 \mathrm{ml} 20 \mathrm{mM}$ HEPES pH 8.0 and the suspension was ultracentrifuged at $100,000 \mathrm{~g}$ during $30 \mathrm{~min}$ at $4{ }^{\circ} \mathrm{C}$. Total membranes were pelleted and resuspended in $1.5 \mathrm{ml}$ of $20 \mathrm{mM}$ HEPES $\mathrm{pH} 8.0+15 \mu$ TRITON X-100, ultracentrifuged at $100,000 \mathrm{~g}$ during $1 \mathrm{~h}$ at $4{ }^{\circ} \mathrm{C}$. Outer membranes were in the pellet and inner membranes were enriched in the supernatant. Inner membranes were collected. The pellet was washed in $1.5 \mathrm{ml}$ of $20 \mathrm{mM}$ HEPES pH 8.0, ultracentrifuged at $100,000 \mathrm{~g}$ during $1 \mathrm{~h}$ at $4{ }^{\circ} \mathrm{C}$ and the pellet, enriched in outer membranes, was resuspended in $300 \mu \mathrm{l}$ of 20 mM HEPES pH 8.0.

One hundred $\mu \mathrm{g}$ of the different PAO1 cytoplasmic extracts were loaded onto conventional SDS-PAGE 10\% Bis-Tris gels (mini-protean TGX Stain-free precast Gels, BioRad). The gel was stained with Coomassie blue and each lane was cut into 10 bands. Gel slices were cut into $1 \mathrm{~mm}^{3}$ cubes, washed twice with water and dehydrated with $100 \%$ ACN $(v / \mathrm{v})$.

One hundred $\mu \mathrm{g}$ of protein of subproteomes (outer and inner membranes and T3SS secretome) were loaded in a conventional SDS-PAGE gel ( $1 \mathrm{~mm}$-thick, $4 \%$ stacking, and $12 \%$ resolving). Then run was stopped as soon as the front entered the resolving gel, so that the whole proteome became concentrated in the stacking/resolving gel interface. The unseparated protein bands were visualized by Coomassie staining, excised, cut into cubes $\left(1 \mathrm{~mm}^{3}\right)$, washed twice with water, and dehydrated with $100 \% \operatorname{ACN}(v / v)$. All the gel slices were incubated with 10 $\mathrm{mM}$ DTT in $50 \mathrm{mM} \mathrm{NH}_{4} \mathrm{HCO}_{3}$ for $30 \mathrm{~min}$ at $56{ }^{\circ} \mathrm{C}$ for protein reduction; alkylation was carried out with $50 \mathrm{mM}$ iodoacetamide (IAA) in $50 \mathrm{mM}$ ammonium bicarbonate solution.

The gel pieces were washed with $50 \% \operatorname{ACN}(\mathrm{v} / \mathrm{v})$, and then washed again with $10 \mathrm{mM} \mathrm{NH}_{4} \mathrm{HCO}_{3}$, dehydrated with $100 \% \mathrm{ACN}(\mathrm{v} / \mathrm{v})$, and then dried in a vacuum concentrator. The gel pieces were rehydrated by adding sequence grade-modified trypsin (Roche) $1: 20$ in $50 \mathrm{mM}$ $\mathrm{NH}_{4} \mathrm{HCO}_{3}$ and incubated overnight at room temperature in the dark for protein digestion. Supernatants were transferred to clean tubes, and gel pieces were incubated in $50 \mathrm{mM} \mathrm{NH}{ }_{4} \mathrm{HCO}_{3}$ at $50{ }^{\circ} \mathrm{C}$ for $1 \mathrm{~h}$. Then, remaining peptides were collected by incubation with $5 \%$ formic acid for $15 \mathrm{~min}$ and with $100 \%$ ACN for 15 min more. The extracts were combined, and the organic solvent was removed in a vacuum concentrator.

The tryptic eluted peptides were dried by speed-vacuum centrifugation and then desalted onto StageTip C18 Pipette tips (Thermo Scientific) until the mass spectrometric analysis. The 10 slices of the whole proteomes were combined, and 5 fractions were used for the mass spectrometry analysis.

\subsection{LC-MS/MS analysis}

The MS system used was an LTQ XL Orbitrap (ThermoFisher) equipped with a nanoESI ion source. A total amount of $5 \mu \mathrm{g}$ from each sample (volume of $20 \mu$ l) was loaded into the chromatographic system consisting in a $\mathrm{C} 18$ pre-concentration cartridge (Agilent Technologies) connected to a $360 \mathrm{~cm}$ long, $100 \mu \mathrm{m}$ i.d. C18 column (NanoSeparations). The separation was done at $0.25 \mu \mathrm{l} / \mathrm{min}$ in a $360 \mathrm{~min}$ acetonitrile gradient from 3 to $40 \%$ (solvent A: $0.1 \%$ formic acid, solvent B: acetonitrile $0.1 \%$ formic acid). The HPLC system was composed of an Agilent 1200 capillary nano pump, a binary pump, a thermostated micro injector and a micro switch valve. The LTQ XL Orbitrap was operated in the positive ion mode with a spray voltage of $1.8 \mathrm{kV}$. The spectrometric analysis was performed in a data dependent mode, acquiring a full scan followed by $10 \mathrm{MS} / \mathrm{MS}$ scans of the 10 most intense signals detected in the MS scan from the global list. The full MS (range 400-1800) was acquired in the Orbitrap with a resolution of 60,000 . The MS/MS spectra were done in the linear ion-trap.

\subsection{Compiling of additional P. aeruginosa datasets}

\subsubsection{Datasets from our group}

In addition to the current proteomes analyzed, three different $P$. aeruginosa MS/MS datasets from our lab were compiled to contribute to the $P$. aeruginosa PeptideAtlas, extending the coverage in two more specific conditions, the secretome of PAO1 compared with the mutant FCP001 (EVs and EV-free secre- tome) [24], and the comparison of the whole proteomes of PAO1 and mutant strain FCP001 grown until under exponential phase of growth [41].

Besides, the proteomic data from an experiment designed to compare the labelling by iTRAQ using the following kits: 4-plex, 6-plex ( 6 of the 8-plex kit markers) and 8-plex was added. For these experiments, 4, 6 or 8 biological replicates from the whole proteome of PAO1 grown until exponential phase growth were used. Briefly, 8 independent cultures of PAO1 (20 $\mathrm{ml}$ of each) were grown in LB medium to reach midexponential growth phase $\left(\mathrm{OD}_{600}\right.$ of 0.6$)$, moment at which the cells were pelleted by centrifugation and proteins were obtained in $1 \mathrm{ml}$ of PBS supplemented with 1/1000 Protease Inhibitor Cocktail (Complete, Mini, EDTA-free Protease Inhibitor Cocktail Tablets) by sonication. Forty $\mu \mathrm{g}$ of protein from each condition were precipitated with methanol/chloroform and resuspended in $0.5 \mathrm{M}$ Triethylammonium bicarbonate (TEAB) and after trypsin digestion, samples were labeled at room temperature for $2 \mathrm{~h}$ with a half unit of iTRAQ Reagent Multi-plex kit (AB SCIEX, Foster City, CA, USA). Finally, samples were combined and bRPLC C18 fractionation of the iTRAQ labeled peptides was performed on the Smartline (Knauer, Germany) HPLC system using the Waters, XBridge C18 column $(100 \times 2.1 \mathrm{~mm}, 5 \mu \mathrm{m}$ particle). Thirty fractions were collected over the elution profile and pooled into 5 fractions. The peptide fractions were dried, desalted using a SEP-PAK C18 Cartridge (Waters) and stored at $-20{ }^{\circ} \mathrm{C}$ until the LC - MS analysis.

A $1.5 \mu \mathrm{g}$ aliquot of each peptide fraction was subjected to 2D-nano LC ESI-MSMS analysis using a nano liquid chromatography system (Eksigent Technologies nanoLC Ultra 1D plus, AB SCIEX, Foster City, CA) coupled to high speed Triple TOF 5600 mass spectrometer (AB SCIEX, Foster City, CA) with a Nanospray III Source. The loading pump delivered a solution of $0.1 \%$ formic acid in water at $2 \mu \mathrm{l} / \mathrm{min}$. The nano-pump provided a flow-rate of $300 \mathrm{nl} / \mathrm{min}$ and was operated under gradient elution conditions, using $0.1 \%$ formic acid in water as mobile phase A, and $0.1 \%$ formic acid in acetonitrile as mobile phase B. Gradient elution was performed using a 120 min gradient ranging from $2 \%$ to $90 \%$ mobile phase B. Injection volume was $5 \mu \mathrm{l}$.

Data acquisition was performed with a TripleTOF 5600 System (AB SCIEX, Concord, ON). Data were acquired using an ionspray voltage floating (ISVF) $2800 \mathrm{~V}$, curtain gas (CUR) 20, interface heater temperature (IHT) 150, ion source gas 1 (GS1) 20, declustering potential (DP) $85 \mathrm{~V}$. All data were acquired using information-dependent acquisition 
(IDA) mode with Analyst TF 1.5 software (AB SCIEX, USA). For IDA parameters, $0.25 \mathrm{~s}$ MS survey scan in the mass range of 350-1250 Da were followed by $30 \mathrm{MS} / \mathrm{MS}$ scans of $150 \mathrm{~ms}$ in the mass range of 100-1800 (total cycle time: $4.04 \mathrm{~s}$ ). Switching criteria were set to ions greater than mass to charge ratio $(\mathrm{m} / \mathrm{z}) 350$ and smaller than $\mathrm{m} / \mathrm{z} 1250$ with charge state of 2-5 and an abundance threshold of more than 90 counts (cps). Former target ions were excluded for 20 s. IDA rolling collision energy (CE) parameters script was used for automatically controlling the $\mathrm{CE}$.

\subsubsection{Other PRIDE P. aeruginosa datasets}

Together with the experiments from our group, other published works that have been uploaded to the public repository PRIDE [42] have been included to increase the coverage of the $P$. aeruginosa PeptideAtlas. These are the datasets from Herbst et al. (PXD001373) [43], sample 15, Penesyan et al. (PXD002865) [44], sample 16, Casabona et al. (PXD000107) [45], sample 17, and Robert-Genthon et al. (PXD000189) [46], samples 18 and 19 (Table 1, Fig. 1).

\subsection{Post spectra acquisition processing}

LC-MS/MS spectra files resulting from the different proteomes (Fig. 1), in their native vendor-specific format, along with the meta data corresponding to each approach, were submitted to PeptideAtlas via the PeptideAtlas Submission System (PASS) on-line submission form with dataset identifications: PASS00799, PASS00800, PASS00801, PASS00802, PASS00803, PASS00804, PASS00805, PASS00806, PASS00807, PASS00808, PASS00809, PASS00821 and PASS00822, together with the already included in PRIDE previously cited. LC-MS/ MS spectra files were converted to XML-based HUPO-PSI-adopted standard format for mass spectrometry output, mzML [47]. The protein sequence FASTA file was obtained from the Pseudomonas Genome Database (www.pseudomonas.com) [35]. Sequences were appended with a set of common contaminant proteins from the cRAP (common Repository of Adventitious Proteins) set from the GPM (http://www.th egpm.org/crap/) and decoy counterparts for every entry to add up a total of 11,376 entries.

Then database searches were performed using three different search engines: Comet [48], an open-source, freely available version of SEQUEST [49], X!Tandem [50] with the k-score algorithm plugin [51], and OMSSA [52]. The search parameters were established depending on the type of experiment and instrument (see supplementary table S1 'database_search_parameters' for a list of parameters).

Following sequence database searching, we used the TPP (TransProteomic Pipeline) tool suite [53,54] to validate the results. First, PeptideProphet [55] creates a discriminant search engine-independent score, models distributions of correctly and incorrectly assigned peptide spectrum matches (PSMs) and computes PSM posterior probabilities. Next, iProphet [56], was used to combine three search results, further refine the PSM-level probabilities and calculate distinct peptidelevel probabilities using corroborating information from other PSMs in the dataset. ProteinProphet [57] then was used to further refine peptide probabilities based on the Number of Sibling Peptides (NSP) that each peptide shares within a protein; it also groups and reports proteins with a protein-level probability estimated from peptide-level probabilities. To assemble the $P$. aeruginosa PeptideAtlas, all individual iProphet files from the 13 compiled datasets were filtered at a variable probability threshold to reach a constant PSM-level FDR threshold of 0.0002 across all datasets.

The Pseudomonas aeruginosa PeptideAtlas is made available at https ://db.systemsbiology.net/sbeams/cgi/PeptideAtlas/buildDetails?atlas_ build_id $=455$.

Mayu [58] software, designed for large-scale protein FDR estimation, was used to report FDR values at different levels (PSM, unique peptides and protein-level) for the whole build based on a strategy that estimates the number of false positive protein identifications from the number of proteins containing false positive PSMs, including a correction for high proteome coverage.

\subsection{In silico functional analyses}

Gene Ontology classifications, and subcellular protein localization studies were performed using the Pseudomonas Genome Database (www. pseudomonas.com) [35] and KEGG PATHWAY Database (https://www. genome.jp/kegg/) was used for pathway analysis $[59,60]$.

\section{Results and discussion}

\subsection{Construction of the P. aeruginosa PeptideAtlas and strategies for exhaustive proteome characterization}

The Pseudomonas PeptideAtlas has been built using data mainly obtained from the wild-type strain PAO1, one of the most widely used model strains, whose genome sequence is available [61]. We used a wide range of experimental growth conditions and different subcellular fractions to increase the proteome coverage as much as possible (Fig. 1 and Table 1). Table 1 and Supplemental Table S2 show the number of proteins identified in the different samples. In Table S2, proteins are ordered by number in the Pseudomonas Genome Database (www.pseudo monas.com) [35], facilitating the visualization of the identified proteins in the different conditions to observe commonalities and differences between conditions. Uniquely identified proteins in each dataset are highlighted. Of the total 649 uniquely identified proteins, 164 belong to the datasets generated by our group. This shows the necessity of analyzing of proteomes produced under different environmental conditions.

Samples 1 and 2 were obtained from PAO1 and the mutant strain Fcp001 $(\Delta c r c)$ grown until they reached the exponential phase of growth at $37^{\circ} \mathrm{C}$. In the work by Corona et al. [41], the whole proteomes were studied (Sample 1), and in the case of Reales-Calderon et al. [24], the fraction used was the secretome (Sample 2). In both cases, proteins were labeled with iTRAQ and analyzed by LC-MS/MS. In sample 1, 2762 proteins were identified in a total of 30 runs, 51 of them unique to sample 1 and in sample 2, a total of 1265 proteins in the secretome and EVs were identified in 12 runs, 12 of them only detected in this sample. The same growth conditions were used for samples 8,9 , and 10 , allowing the identification of around 1550 proteins in each experiment. The difference between these samples was the iTRAQ labeling strategy, with 4, 6, or 8 plex used. Only two runs were done for each sample. As expected, the three samples differed only in a few proteins (Table S2), allowing the addition of peptides from 7 more proteins to PeptideAtlas. All of them were grown until the exponential phase of growth, a condition widely used for microbiological studies, with the expectation that many proteins should be abundant because the microorganism is actively growing. However, the stationary phase of growth can unveil proteins that are important for the maintenance of the microorganism once the carbon source has been exhausted and secreted components are accumulating in the culture. This condition is represented by sample 13, which comprises 2504 proteins, including 18 not detected in the other samples.

For sample 3, anaerobic conditions were used because, during chronic infection of the CF lung, $P$. aeruginosa is able to grow and persist in a microaerobic to anaerobic environment [62]. This analysis rendered 2252 proteins, 20 of them uniquely identified in this sample. Growth as a biofilm is very important in $P$. aeruginosa virulence and antibiotic resistance [14], in its persistence in environments such as water supplies [63], and in CF patients [3]. Samples 4, 15, and 16 represent this kind of growth. In sample 4, 1689 proteins were identified, including 15 unique for this sample.

As $P$. aeruginosa is present in natural environments, we grew PAO1 at $20^{\circ} \mathrm{C}$ (sample 5). In 5 runs, 2313 proteins were identified, of which only 6 were uniquely detected in this condition. Because $P$. aeruginos $a$ is quite 


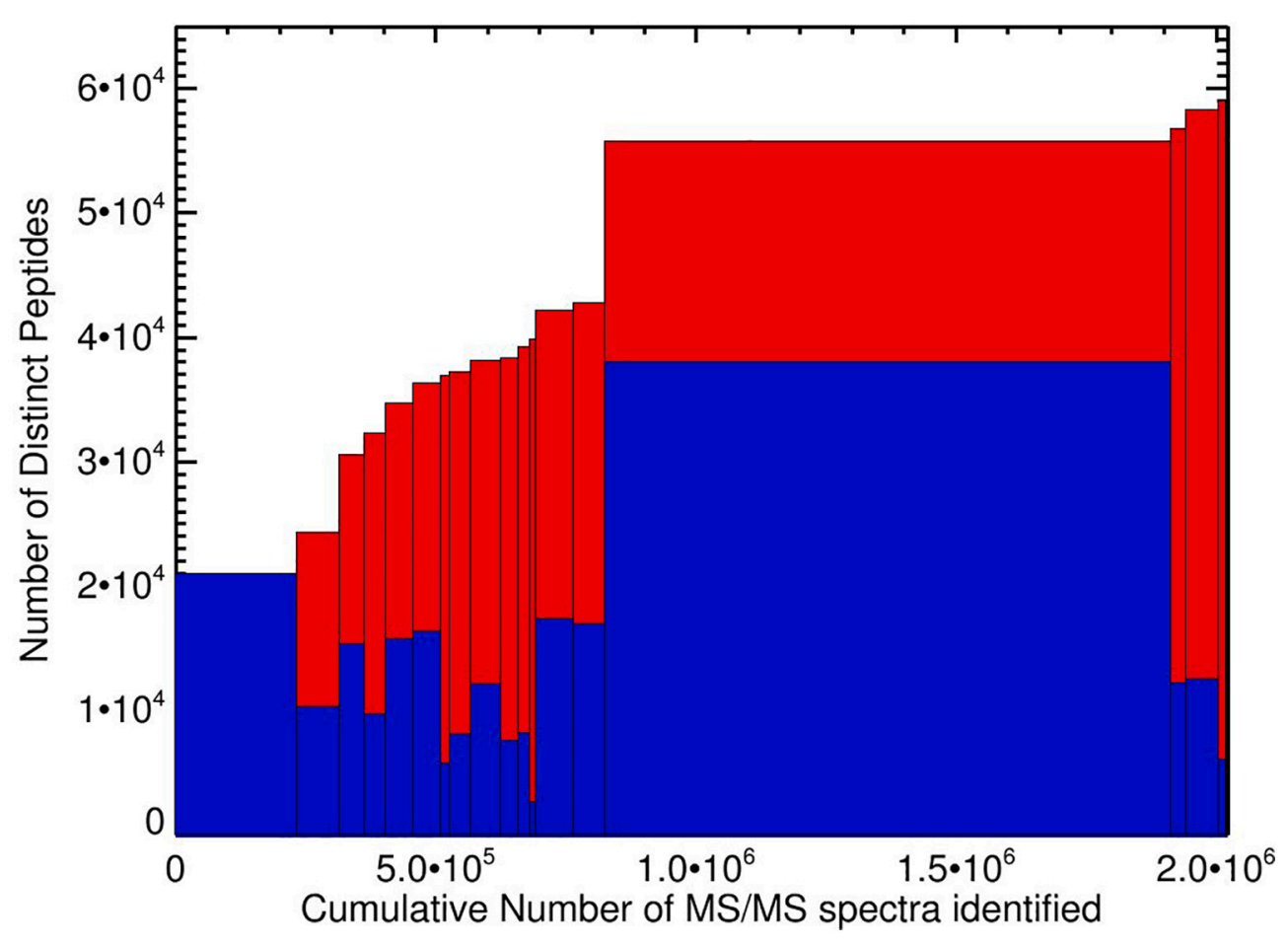

Fig. 2. Contribution of the different constituent datasets of the Pseudomonas PeptideAtlas. Plot shows the number of peptides contributed by each experiment, and the cumulative number of distinct peptides for the build as of that experiment. For each dataset, the height of the blue bar represents the number of distinct peptides and the total height of bar represents the cumulative number of distinct peptides identified. The width of bars represents the contributions in terms of spectra identified. Numbers designate the samples as ordered in Table 1. (For interpretation of the references to colour in this figure legend, the reader is referred to the web version of this article.) resistant to antibiotics [14,20] and it has been reported that subinhibitory antibiotic concentrations may modify $P$. aeruginosa physiology [64], sample 6, grown in tetracycline (TCN) was included, with 2465 proteins identified, including 13 more unique to this condition. In addition, PAO1 was cultured in the medium that induces the type III secretion system (T3SS), as T3SS is a very important virulence factor, and the proteome and secretome were analyzed (samples 14 and 12, respectively). This condition yielded a total of more than 2800 identified proteins from the two samples, including 15 that were unique to them.

Cytosolic extracts are the most commonly studied fractions in proteomic analysis, but some proteins are under-represented in or missing from them, for instance membrane proteins [65]. With the goal of maximum coverage of the proteome, subcellular fractions enriched in membrane proteins (samples 7 and 11) were also analyzed, and 7 more unique proteins were identified. According to Pseudomonas Genome Database, in sample 7, from the total of 1158 proteins, 199 are membrane proteins, while in sample 11, of the total 1080 proteins identified, there are 290 membrane proteins. As part of the datasets from other authors included in the PeptideAtlas, sample 17 [45], is described as an inner membrane enriched proteome, with 670 membrane proteins and 18 proteins uniquely identified in this sample.

Besides, proteins identified in other published works $[24,41,43,44,46]$ were also included, adding 529 more uniquely identified proteins to the PeptideAtlas (Samples 15, 16, 18 and 19). Penesyan et al. [44] (Sample 16) included proteins from four clinical isolates. As expected, the proteomes of these freshly isolated strains differ from that of the PAO1 strain, as only $29.4 \%$ of the identified proteins were common to all 5 strains used in this work. Although this does not mean that the proteins are not present in all these strains, it is a sign of differences in the most abundant proteins between samples showing, as the authors highlight, the need for analyses of strains isolated from clinical or environmental samples [44]. Sample 16 contributed with 1787 proteins, of which 223 were uniquely identified. The dataset with the highest number of proteins identified is sample 15 [43] with 3698, and it also comprises the highest number of unique proteins, 240.

A total of 5,078,535 tandem mass (MS/MS) spectra from the 19 different proteomic experiments and 459 individual runs using a wide variety of mass spectrometers (TripleTOF 5600, LTQ Orbitrap XL, LTQOrbitrap Velos, LTQ Orbitrap Velos pro and Q Exactive) were used to generate the $P$. aeruginosa PeptideAtlas. Almost $40 \%(2,021,521)$ of the generated spectra were matched to peptides with probability high enough to pass our threshold. From these, 13,059 peptides were identified in only one dataset. Sample 15, with the highest number of runs (288), contained 2,516,514 spectra. Overviews of the contributions of each dataset to the entirety of the PeptideAtlas build are depicted in Table 1 and in Fig. 2.

As above stated, $P$. aeruginosa is one of the most prevalent opportunistic human pathogens. It is able to grow as biofilm, under aerobic and anaerobic conditions and in diverse host environments. Besides, it harbours several antibiotic resistance determinants, the expression of which is a relevant problem for the treatment of the infections it produces. Consequently, the exploration of growth conditions such as biofilm formation, anaerobic growth, in the presence of antibiotics, or situations that trigger T3SS, is crucial for the analysis of proteins involved in virulence and antibiotic resistance. Particularly relevant is the study of the exoproteome and the EVs-associated proteome since several $P$. aeruginosa virulence determinants are extracellular. Thus, the total of peptides and proteins included in the Pseudomonas PeptideAtlas Database, together with the information on the conditions used to trigger them, make the database a powerful tool for implementing targeted proteomic approaches aiming to track proteomic changes associated with infecting conditions as well as to analyze the expression of proteins involved in $P$. aeruginosa antibiotic resistance.

\subsection{Functional and gene ontology enrichment analyses of the proteins included in the P. aeruginosa PeptideAtlas}

The proteomic analyses identified 4043 proteins from a total of 5668 proteins predicted to be encoded by the $P$. aeruginosa PAO1 genome, achieving $71.3 \%$ coverage of the predicted Pseudomonas proteome. Table 2 lists the more represented KEGG pathways, and those with coverage superior to $90 \%$ are highlighted. The proteins in the Pseudomonas PeptideAtlas cover $89 \%$ of metabolic proteins, $72 \%$ of proteins involved in genetic information processing, $83 \%$ of proteins responsible 
Table 2

KEGG pathway enrichment analysis.

\begin{tabular}{|c|c|c|c|}
\hline KEGG identifiers and KEGG pathway maps & $\begin{array}{c}\text { Identified } \\
\text { proteins }\end{array}$ & $\begin{array}{l}\text { Total protein in } \\
\text { KEGG pathway maps }\end{array}$ & $\begin{array}{l}\text { Percent of protein } \\
\text { in Peptide Atlas* }\end{array}$ \\
\hline \multicolumn{4}{|l|}{ 1. Metabolism } \\
\hline \multicolumn{4}{|l|}{ Global and overview maps } \\
\hline 01200 Carbon metabolism & 120 & 124 & 96.77 \\
\hline 01210 2-Oxocarboxylic acid metabolism & 28 & 30 & 93.33 \\
\hline 01212 Fatty acid metabolism & 42 & 49 & 85.71 \\
\hline 01230 Biosynthesis of amino acids & 136 & 146 & 93.15 \\
\hline 01240 Biosynthesis of cofactors & 166 & 185 & 89.73 \\
\hline 01220 Degradation of aromatic compounds & 10 & 28 & 35.71 \\
\hline \multicolumn{4}{|l|}{ Carbohydrate metabolism } \\
\hline 00010 Glycolysis / Gluconeogenesis & 34 & 37 & 91.89 \\
\hline 00020 Citrate cycle (TCA cycle) & 31 & 31 & 100.00 \\
\hline 00030 Pentose phosphate pathway & 24 & 27 & 88.89 \\
\hline $\begin{array}{l}00040 \text { Pentose and glucuronate } \\
\text { interconversions }\end{array}$ & 4 & 7 & 57.14 \\
\hline 00051 Fructose and mannose metabolism & 17 & 19 & 89.47 \\
\hline 00052 Galactose metabolism & 4 & 5 & 80.00 \\
\hline 00053 Ascorbate and aldarate metabolism & 4 & 6 & 66.67 \\
\hline 00500 Starch and sucrose metabolism & 14 & 16 & 87.50 \\
\hline $\begin{array}{l}00520 \text { Amino sugar and nucleotide sugar } \\
\text { metabolism }\end{array}$ & 36 & 37 & 97.30 \\
\hline 00620 Pyruvate metabolism & 58 & 62 & 93.55 \\
\hline $\begin{array}{l}00630 \text { Glyoxylate and dicarboxylate } \\
\text { metabolism }\end{array}$ & 54 & 59 & 91.53 \\
\hline 00640 Propanoate metabolism & 41 & 43 & 95.35 \\
\hline 00650 Butanoate metabolism & 34 & 42 & 80.95 \\
\hline 00660 C5-Branched dibasic acid metabolism & 12 & 14 & 85.71 \\
\hline 00562 Inositol phosphate metabolism & 6 & 7 & 85.71 \\
\hline \multicolumn{4}{|l|}{ Energy metabolism } \\
\hline 00190 Oxidative phosphorylation & 51 & 57 & 89.47 \\
\hline 00680 Methane metabolism & 25 & 26 & 96.15 \\
\hline 00910 Nitrogen metabolism & 30 & 34 & 88.24 \\
\hline 00920 Sulfur metabolism & 35 & 49 & 71.43 \\
\hline \multicolumn{4}{|l|}{ Lipid metabolism } \\
\hline 00061 Fatty acid biosynthesis & 24 & 26 & 92.30 \\
\hline 00071 Fatty acid degradation & 26 & 31 & 83.87 \\
\hline $\begin{array}{l}00072 \text { Synthesis and degradation of ketone } \\
\text { bodies }\end{array}$ & 9 & 10 & 90.00 \\
\hline 00561 Glycerolipid metabolism & 12 & 15 & 80.00 \\
\hline 00564 Glycerophospholipid metabolism & 23 & 26 & 88.46 \\
\hline 00565 Ether lipid metabolism & 2 & 3 & 66.67 \\
\hline 00590 Arachidonic acid metabolism & 3 & 4 & 75.00 \\
\hline 00592 alpha-Linolenic acid metabolism & 2 & 3 & 66.67 \\
\hline 01040 Biosynthesis of unsaturated fatty acids & 5 & 5 & 100.00 \\
\hline \multicolumn{4}{|l|}{ Nucleotide metabolism } \\
\hline 00230 Purine metabolism & 61 & 68 & 89.70 \\
\hline 00240 Pyrimidine metabolism & 28 & 33 & 84.85 \\
\hline \multicolumn{4}{|l|}{ Amino acid metabolism } \\
\hline $\begin{array}{l}00250 \text { Alanine, aspartate and glutamate } \\
\text { metabolism }\end{array}$ & 34 & 37 & 91.89 \\
\hline $\begin{array}{l}00260 \text { Glycine, serine and threonine } \\
\text { metabolism }\end{array}$ & 46 & 49 & 93.88 \\
\hline 00270 Cysteine and methionine metabolism & 40 & 43 & 93.02 \\
\hline 00280 Valine, leucine and isoleucine & 41 & 46 & 89.13 \\
\hline
\end{tabular}




\begin{tabular}{|c|c|c|c|}
\hline KEGG identifiers and KEGG pathway maps & $\begin{array}{l}\text { Identified } \\
\text { proteins }\end{array}$ & $\begin{array}{l}\text { Total protein in } \\
\text { KEGG pathway maps }\end{array}$ & $\begin{array}{l}\text { Percent of protein } \\
\text { in Peptide Atlas* }\end{array}$ \\
\hline \multicolumn{4}{|l|}{ degradation } \\
\hline $\begin{array}{l}00290 \text { Valine, leucine and isoleucine } \\
\text { biosynthesis }\end{array}$ & 18 & 19 & 94.74 \\
\hline 00300 Lysine biosynthesis & 14 & 15 & 93.33 \\
\hline 00310 Lysine degradation & 19 & 22 & 86.36 \\
\hline 00220 Arginine biosynthesis & 28 & 29 & 96.55 \\
\hline 00330 Arginine and proline metabolism & 39 & 49 & 79.59 \\
\hline 00340 Histidine metabolism & 23 & 24 & 95.83 \\
\hline 00350 Tyrosine metabolism & 15 & 27 & 55.56 \\
\hline 00360 Phenylalanine metabolism & 22 & 27 & 81.48 \\
\hline 00380 Tryptophan metabolism & 28 & 31 & 90.32 \\
\hline $\begin{array}{l}00400 \text { Phenylalanine, tyrosine and tryptophan } \\
\text { biosynthesis }\end{array}$ & 27 & 30 & 90.00 \\
\hline \multicolumn{4}{|l|}{ Metabolism of other amino acids } \\
\hline 00410 beta-Alanine metabolism & 18 & 20 & 80.00 \\
\hline 00430 Taurine and hypotaurine metabolism & 7 & 8 & 87.50 \\
\hline $\begin{array}{l}00440 \text { Phosphonate and phosphinate } \\
\text { metabolism }\end{array}$ & 2 & 9 & 22.22 \\
\hline 00450 Selenocompound metabolism & 9 & 9 & 100.00 \\
\hline 00460 Cyanoamino acid metabolism & 11 & 11 & 100.00 \\
\hline $\begin{array}{l}00471 \text { D-Glutamine and D-glutamate } \\
\text { metabolism }\end{array}$ & 5 & 5 & 100.00 \\
\hline 00472 D-Arginine and D-ornithine metabolism & 2 & 2 & 100.00 \\
\hline 00473 D-Alanine metabolism & 4 & 4 & 100.00 \\
\hline 00480 Glutathione metabolism & 28 & 29 & 96.55 \\
\hline \multicolumn{4}{|l|}{ Glycan biosynthesis and metabolism } \\
\hline 00540 Lipopolysaccharide biosynthesis & 27 & 28 & 96.43 \\
\hline $\begin{array}{l}00541 \text { O-Antigen nucleotide sugar } \\
\text { biosynthesis }\end{array}$ & 24 & 25 & 96.00 \\
\hline 00550 Peptidoglycan biosynthesis & 19 & 20 & 95.00 \\
\hline \multicolumn{4}{|l|}{ Metabolism of cofactors and vitamins } \\
\hline 00730 Thiamine metabolism & 12 & 13 & 92.31 \\
\hline 00740 Riboflavin metabolism & 9 & 12 & 75.00 \\
\hline 00750 Vitamin B6 metabolism & 8 & 9 & 88.89 \\
\hline $\begin{array}{l}00760 \text { Nicotinate and nicotinamide } \\
\text { metabolism }\end{array}$ & 23 & 24 & 95.83 \\
\hline 00770 Pantothenate and CoA biosynthesis & 21 & 26 & 80.77 \\
\hline 00780 Biotin metabolism & 19 & 21 & 90.48 \\
\hline 00785 Lipoic acid metabolism & 2 & 2 & 100.00 \\
\hline 00790 Folate biosynthesis & 29 & 32 & 90.63 \\
\hline 00670 One carbon pool by folate & 17 & 18 & 94.44 \\
\hline 00860 Porphyrin and chlorophyll metabolism & 40 & 47 & 85.11 \\
\hline $\begin{array}{l}00130 \text { Ubiquinone and other terpenoid- } \\
\text { quinone biosynthesis }\end{array}$ & 17 & 18 & 94.44 \\
\hline \multicolumn{4}{|l|}{ Metabolism of terpenoids and polyketides } \\
\hline 00900 Terpenoid backbone biosynthesis & 15 & 16 & 93.75 \\
\hline 00903 Limonene and pinene degradation & 7 & 8 & 87.50 \\
\hline 00281 Geraniol degradation & 14 & 17 & 82.35 \\
\hline 00523 Polyketide sugar unit biosynthesis & 5 & 5 & 100.00 \\
\hline $\begin{array}{l}01053 \text { Biosynthesis of siderophore group } \\
\text { nonribosomal peptides }\end{array}$ & 7 & 7 & 100.00 \\
\hline \multicolumn{4}{|l|}{ Biosynthesis of other secondary metabolites } \\
\hline 00332 Carbapenem biosynthesis & 2 & 2 & 100.00 \\
\hline 00261 Monobactam biosynthesis & 8 & 9 & 88.89 \\
\hline 00521 Streptomycin biosynthesis & 8 & 8 & 100.00 \\
\hline 00525 Acarbose and validamycin biosynthesis & 2 & 2 & 100.00 \\
\hline 00401 Novobiocin biosynthesis & 5 & 5 & 100.00 \\
\hline
\end{tabular}




\begin{tabular}{|c|c|c|c|}
\hline KEGG identifiers and KEGG pathway maps & $\begin{array}{c}\text { Identified } \\
\text { proteins }\end{array}$ & $\begin{array}{c}\text { Total protein in } \\
\text { KEGG pathway maps }\end{array}$ & $\begin{array}{l}\text { Percent of protein } \\
\text { in Peptide Atlas* }\end{array}$ \\
\hline 00405 Phenazine biosynthesis & 24 & 24 & 100.00 \\
\hline \multicolumn{4}{|l|}{ Xenobiotics biodegradation and metabolism } \\
\hline 00362 Benzoate degradation & 22 & 35 & 62.86 \\
\hline $\begin{array}{l}00625 \text { Chloroalkane and chloroalkene } \\
\text { degradation }\end{array}$ & 6 & 8 & 75.00 \\
\hline $\begin{array}{l}00361 \text { Chlorocyclohexane and chlorobenzene } \\
\text { degradation }\end{array}$ & 1 & 6 & 16.67 \\
\hline 00633 Nitrotoluene degradation & 2 & 2 & 100.00 \\
\hline 00643 Styrene degradation & 8 & 12 & 66.67 \\
\hline 00930 Caprolactam degradation & 8 & 9 & 88.89 \\
\hline 00626 Naphthalene degradation & 2 & 2 & 100.00 \\
\hline \multicolumn{4}{|l|}{$\begin{array}{l}\text { 2. Genetic Information Processing } \\
\text { Transcription }\end{array}$} \\
\hline 03020 RNA polymerase & 4 & 4 & 100.00 \\
\hline \multicolumn{4}{|l|}{ Translation } \\
\hline 03010 Ribosome & 55 & 68 & 80.88 \\
\hline 00970 Aminoacyl-tRNA biosynthesis & 27 & 90 & 30.00 \\
\hline \multicolumn{4}{|l|}{ Folding, sorting and degradation } \\
\hline 03060 Protein export & 17 & 18 & 94.44 \\
\hline 04122 Sulfur relay system & 20 & 21 & 95.24 \\
\hline 03018 RNA degradation & 16 & 17 & 94.12 \\
\hline \multicolumn{4}{|l|}{ Replication and repair } \\
\hline 03030 DNA replication & 14 & 15 & 93.33 \\
\hline 03410 Base excision repair & 12 & 13 & 92.31 \\
\hline 03420 Nucleotide excision repair & 8 & 8 & 100.00 \\
\hline 03430 Mismatch repair & 16 & 17 & 94.12 \\
\hline 03440 Homologous recombination & 22 & 23 & 95.65 \\
\hline \multicolumn{4}{|l|}{ 3. Environmental Information Processing } \\
\hline \multicolumn{4}{|l|}{ Membrane transport } \\
\hline 02010 ABC transporters & 151 & 193 & 78.24 \\
\hline 02060 Phosphotransferase system (PTS) & 8 & 8 & 100.00 \\
\hline 03070 Bacterial secretion system & 64 & 92 & 69.57 \\
\hline \multicolumn{4}{|l|}{ Signal transduction } \\
\hline 02020 Two-component system & 194 & 212 & 91.51 \\
\hline \multicolumn{4}{|l|}{ 4. Cellular Processes } \\
\hline \multicolumn{4}{|l|}{ Cellular community - prokaryotes } \\
\hline 02024 Quorum sensing & 84 & 95 & 88.42 \\
\hline $\begin{array}{l}02025 \text { Biofilm formation - Pseudomonas } \\
\text { aeruginosa }\end{array}$ & 102 & 113 & 90.27 \\
\hline \multicolumn{4}{|l|}{ Cell motility } \\
\hline 02030 Bacterial chemotaxis & 46 & 46 & 100.00 \\
\hline 02040 Flagellar assembly & 41 & 46 & 89.13 \\
\hline \multicolumn{4}{|l|}{ 5. Human Diseases } \\
\hline \multicolumn{4}{|l|}{ Drug resistance: Antimicrobial } \\
\hline 01501 beta-Lactam resistance & 24 & 27 & 88.89 \\
\hline 01502 Vancomycin resistance & 8 & 8 & 100.00 \\
\hline $\begin{array}{l}01503 \text { Cationic antimicrobial peptide (CAMP) } \\
\text { resistance }\end{array}$ & 24 & 28 & 85.71 \\
\hline
\end{tabular}

*KEGG pathways represented in a percentage higher than $90 \%$ are highlighted.

for environmental information processing (91\% of two component system proteins), more than $88 \%$ of the ones related to quorum sensing and biofilm formation, and $89 \%$ of proteins responsible for antimicrobial resistance.

The contribution of each sample and the role of some of the proteins included in the PeptideAtlas in processes important for $P$. aeruginosa virulence or adaptation to the conditions studied are discussed below. Processes like iron acquisition, antibiotic resistance, quorum sensing response or response to external inputs, as the two component signal transduction systems, have been included in the analysis.
3.2.1. Proteins relevant to biofilm formation and maintenance

As previously mentioned, samples 4,15 , and 16 were grown as biofilms. When comparing the proteins identified in strains from $\mathrm{CF}$ patients and the proteome of PAO1 biofilm (sample 4), we found 1154 proteins common to both proteomes. Of them, 23 are related to biofilm formation, 33 to the quorum-sensing response, and 19 to antibiotic resistance. In sample 4, of the 15 unique proteins, we found ErcS (PA1976), ErbR (PA1978), EraR (PA1980), and PqqC (PA1987), proteins involved in ethanol oxidation, to be highly expressed in biofilm cells and probably involved in the ciprofloxacin resistance of biofilms [66]. TspR (PA4857), required for T3SS expression, biofilm formation, 
and bacterial motility $[67,68]$, was also found.

In sample 15, in which functional amyloid was induced, 4 of the amyloids, FapE (PA1952), FapD (PA1953), FapC (PA1954), and FapB (PA1955) were uniquely identified [43]. It is also noteworthy, but not surprising, that the genes involved in alginate biosynthesis (PA3540 to PA3551) were identified only in samples 15 and 16, as alginate is the main component of mucoid biofilms and of the $P$. aeruginosa biofilms encountered in CF patients [43,69]. Another group of proteins involved in biofilm formation, the Pel extracellular polysaccharide biosynthetic proteins PelD (PA3061), PelC (PA3062), and PelB (PA3063), were identified only in sample 15. These proteins are the back-up system for the extracellular polysaccharide biosynthetic process for single-species biofilm formation [70] when Psl polysaccharide biosynthesis fails. The proteins for Psl biosynthesis are present in almost all the samples (PA2231-PA2245). We found other proteins related to biofilm formation only in sample 15. These included IcmF3 (PA2361); Arr (PA2818), which is essential for biofilm induction and aminoglycoside resistance [71]; and CupE3 (PA4650) and CupE5 (PA4652), part of the cupE gene cluster that encodes a chaperone usher pathway that is homologous to the Acinetobacter baumanii Csu pili gene cluster and involved in the early and late stages of biofilm formation [72].

CdrA is a cyclic-di-GMP-regulated adhesin that reinforces the extracellular matrix of $P$. aeruginosa biofilm [73]. In accord with its function, it was identified in both biofilm proteomes (samples 4 and 15) and is also common to both secretomes (samples 2 and 12) and is thus determined to be secreted. Mep72 is a metalloendopeptidase [74] common to secretomes and to samples 18 and 19, and it has been described as secreted in biofilms [75].

As previously mentioned, the study of the proteome under anaerobic conditions (sample 3 ) is also interesting because during chronic infection of the CF lung, $P$. aeruginosa is able to grow and persist in a microaerobic to anaerobic environment [62], thus suffering drastic physiological changes. Among the 20 unique proteins in this sample, we highlight PscU (PA1690), PopN (PA1698), ExsB (PA1712), and PscC (PA1716), related to T3SS, which is induced in these conditions [76]. AtvR (PA2899), identified only in sample 15, is an important regulator of the Pseudomonas adaptation to hypoxia and crucial for survival in the host [77].

\subsubsection{Proteins involved in secretion systems}

Microorganisms often relate to their environments by secreting proteins, either by using classic secretion mechanisms, or through extracellular vesicles. Two secretomes with a large proportion of their proteins in common have been included in this study: a secretome obtained during exponential growth, with 12 unique proteins (sample 2), and a secretome sampled under the conditions for T3SS induction (sample 12), with 4 more. With respect to the cytoplasmic proteome under T3SS induction conditions (sample 14), proteins from glycine betaine catabolism [CdhR (PA5389), DgcA (PA5398), GbcB (PA5411), SoxD (PA5417), and SoxA (PA5418)] were detected only in this sample. The generation of glycine betaine via carnitine catabolism allows carnitine to induce the expression of the virulence factor hemolytic phospholipase $\mathrm{C}, \mathrm{PlcH}$ [78], which induces a proinflammatory response, suppresses oxidative burst in neutrophils, degrades pulmonary surfactant, and increases endothelial cell death [79] during infection. Phospholipase $\mathrm{C}$ precursor ( $\mathrm{PlcH}$, PA1249) was detected as a unique protein in the secretome under T3SS induction conditions, which included other virulence factors, such as AprA (PA1249) [80] and the lipase LipA (PA2862) [81]. Thus, the analysis of the proteome under T3SS induction conditions has provided important contributions to the $P$. aeruginosa PeptideAtlas. Proteins involved in T3SS regulation, such as MexT (PA2492) [82], also involved in the regulation of the expression of the multidrug efflux pump MexEF-OprN [83] were identified only in sample 15.

Analysis of the inner and outer membranes of P. aeruginosa PAO1 yielded 25 more unique proteins in datasets 7,11 , and 17 (Table 1). Ten of them are related to transport through membranes or secretion systems. As an example, FleS (PA1098), identified in the outer-membrane proteome, is involved in the regulation of both mucin adhesion and motility [84]. The Tad proteins, involved in the Type II secretion system (PA2494-PA4303), have mostly been identified only in sample 15, and thus might be important for amyloid-induced biofilm growth.

The Type VI secretion system proteins and the proteins secreted are relevant to bacterial pathogenesis and cell survival in the host [85]. All these proteins (PA0070-PA0091) were identified in the amyloidinduced biofilm (sample 15) and many of them in the rest of the samples, together with several VgrG proteins, including VgrG4a (PA3294), VgrG4b (PA3486), VgrG5 (PA5090), and VgrG6 (PA5266), that are also secreted by this system [86].

\subsubsection{Proteins involved in bacterial response to antibiotics}

The study of antibiotic resistance suggests new methods to fight it [87]. Besides, antibiotics can challenge bacterial physiology in some aspects going beyond resistance to these compounds [22].

Thus, the analysis of the proteome under a sub-inhibitory concentration of tetracycline was also included and yielded 2465 proteins. Thirteen were unique, including GltR (PA3192), which is required for glucose transport and involved in the regulation of the expression of exotoxin A, a primary $P$. aeruginosa virulence factor [88]. Biofilms are more resistant to antibiotics, and proteins related to antibiotic resistance were uniquely identified in sample 15. These include PA5514, a probable beta lactamase; PoxB, regulated by AmpR, together with AmpC (PA4110) [89], identified in samples 15 and 16 and in the inner membrane proteome (sample 7); and CzcR (PA2523), which modulates antibiotic, Zn, Cd, and Co resistance [90].

\subsubsection{Proteins involved in iron acquisition}

Iron is a key nutrient that is often in limiting concentrations [91], a situation of particular relevance in the case of infection because bacteria must compete with the host's cells to acquire the iron required for growth. Consequently, siderophores and proteins involved in Fe transport are fundamental to bacterial survival.

FepB (PA4159), an iron-enterobactin transporter, and PfeA (PA2688), a ferric enterobactin receptor, were identified in the secretome of PAO1 (sample 2) [24]. As previously mentioned, PvdS (PA2426) has been identified in cells in stationary phase. PvdS is an RNA polymerase sigma-70 factor from the extracytoplasmic function sigma factor subfamily [92] that controls the synthesis of the siderophore pyoverdine. Its expression is regulated by FpvR (PA2388), a protein present in 6 datasets, and FpvA (PA2398), identified in PAO1 cytosolic extract (sample 9). An increased abundance of the pyoverdine synthesis machinery was observed in sample 15 [43]. In this sample there are several uniquely identified proteins related to iron, such as PvdR (PA2389) and PvdT (PA2390), which are involved in pyoverdine biosynthesis and secretion together with OmpQ (PA2391) [93]; FemA (PA1910), a ferricmycobactin receptor; FvbA (PA4156), a receptor homologous to the one from Vibrio cholerae and able to use vibriobactin as a source of iron in the absence of siderophores [94]; FiuR (PA0471), involved in the uptake of ferrioxiamine B [95] with FiuI (PA0472), in sample 16; FvpG (PA2403) and the rest of the proteins of a putative $\mathrm{ABC}$ transporter complex (PA2404-PA2410); and FoxR (PA2467), part of the Fox cell-surface signaling (CSS) pathway employed by $P$. aeruginosa to sense and respond to the presence of ferrioxamine in the environment. FoxA (PA2466) is the receptor controlled by this system and was identified only in samples 15 and 13 (a stationary phase sample) [96]. These results demonstrate the importance of iron capture and transport for $P$. aeruginosa biofilm growth.

Iron acquisition is also important for survival outside of host. The heme oxygenase Bph0 (PA4116), necessary to yield iron from heme [97], was identified in the sample grown at $20^{\circ} \mathrm{C}$. 
Table 3

Proteins in Pseudomonas PeptideAtlas involved in two component signal transduction systems.

\begin{tabular}{|c|c|}
\hline $\begin{array}{l}\text { Locus } \\
\text { Tag }\end{array}$ & Protein name \\
\hline PA0001 & chromosomal replication initiator protein DnaA \\
\hline PA0112 & hypothetical protein \\
\hline PA0173 & probable methylesterase \\
\hline PA0175 & CheR2 \\
\hline PA0176 & aerotaxis transducer Aer2 \\
\hline PA0177 & probable purine-binding chemotaxis protein \\
\hline PA0178 & probable two-component sensor \\
\hline PA0179 & probable two-component response regulator \\
\hline PA0180 & $\begin{array}{l}\text { chemotactic transducer for trichloroethylene [positive chemotaxis], } \\
\text { CttP }\end{array}$ \\
\hline PA0296 & Glutamylpolyamine synthetase \\
\hline PA0298 & Glutamylpolyamine synthetase \\
\hline PA0408 & twitching motility protein PilG \\
\hline PA0409 & twitching motility protein PilH \\
\hline PA0410 & twitching motility protein PilI \\
\hline PA0411 & twitching motility protein PilJ \\
\hline PA0412 & methyltransferase PilK \\
\hline PA0413 & component of chemotactic signal transduction system \\
\hline PA0414 & probable methylesterase \\
\hline PA0415 & probable chemotaxis protein \\
\hline PA0463 & two-component response regulator $\mathrm{CreB}$ \\
\hline PA0464 & two-component sensor $\mathrm{CreC}$ \\
\hline PA0472 & FiuI \\
\hline PA0518 & cytochrome $c$-551 precursor \\
\hline PA0652 & transcriptional regulator $\mathrm{Vfr}$ \\
\hline PA0749 & hypothetical protein \\
\hline PA0753 & hypothetical protein \\
\hline PA0754 & hypothetical protein \\
\hline PA0756 & probable two-component response regulator \\
\hline PA0757 & probable two-component sensor \\
\hline PA0766 & serine protease $\mathrm{MucD}$ precursor \\
\hline PA0884 & C4-dicarboxylate-binding periplasmic protein \\
\hline PA0886 & probable C4-dicarboxylate transporter \\
\hline PA0905 & RsmA \\
\hline PA0920 & alanyl-phosphatidylglycerol synthase \\
\hline PA0928 & sensor/response regulator hybrid \\
\hline PA0929 & two-component response regulator \\
\hline PA0930 & two-component sensor \\
\hline PA0931 & ferric enterobactin receptor PirA \\
\hline PA0958 & $\begin{array}{l}\text { Basic amino acid, basic peptide and imipenem outer membrane porin } \\
\text { OprD precursor }\end{array}$ \\
\hline PA1092 & flagellin type B \\
\hline PA1097 & transcriptional regulator FleQ \\
\hline PA1098 & two-component sensor \\
\hline PA1099 & two-component response regulator \\
\hline PA1157 & probable two-component response regulator \\
\hline PA1158 & probable two-component sensor \\
\hline PA1179 & two-component response regulator PhoP \\
\hline PA1180 & two-component sensor PhoQ \\
\hline PA1183 & C4-dicarboxylate transport protein \\
\hline PA1251 & chemotaxis transducer \\
\hline PA1335 & AauR \\
\hline PA1336 & AauS \\
\hline PA1337 & glutaminase-asparaginase \\
\hline PA1339 & AatP \\
\hline PA1340 & AatM \\
\hline PA1341 & AatQ \\
\hline PA1342 & putative acidic amino acid $\mathrm{ABC}$ transporter substrate-binding protein \\
\hline PA1423 & BdlA \\
\hline PA1437 & probable two-component response regulator \\
\hline PA1438 & probable two-component sensor \\
\hline PA1455 & sigma factor FliA \\
\hline PA1456 & two-component response regulator $\mathrm{CheY}$ \\
\hline PA1458 & probable two-component sensor \\
\hline PA1459 & probable methyltransferase \\
\hline PA1460 & MotC \\
\hline PA1463 & hypothetical protein \\
\hline PA1464 & probable purine-binding chemotaxis protein \\
\hline PA1552 & Cytochrome c oxidase, cbb3-type, CcoP subunit \\
\hline PA1552 & Cytochrome c oxidase, cbb3-type, CcoQ subunit \\
\hline PA1553 & Cytochrome c oxidase, cbb3-type, CcoO subunit \\
\hline PA1554 & Cytochrome c oxidase, cbb3-type, CcoN subunit \\
\hline
\end{tabular}

Table 3 (continued)

\begin{tabular}{|c|c|}
\hline $\begin{array}{l}\text { Locus } \\
\text { Tag }\end{array}$ & Protein name \\
\hline PA1555 & Cytochrome c oxidase, cbb3-type, CcoP subunit \\
\hline PA1556 & Cytochrome c oxidase, cbb3-type, CcoO subunit \\
\hline PA1557 & Cytochrome c oxidase, cbb3-type, CcoN subunit \\
\hline PA1561 & aerotaxis receptor Aer \\
\hline PA1566 & Glutamylpolyamine synthetase \\
\hline PA1608 & probable chemotaxis transducer \\
\hline PA1611 & hybrid sensor kinase \\
\hline PA1633 & potassium-transporting ATPase, A chain \\
\hline PA1634 & potassium-transporting ATPase, B chain \\
\hline PA1635 & potassium-transporting ATPase, C chain \\
\hline PA1636 & two-component sensor KdpD \\
\hline PA1637 & two-component response regulator $\mathrm{KdpE}$ \\
\hline PA1638 & glutaminase \\
\hline PA1646 & probable chemotaxis transducer \\
\hline PA1736 & probable acyl-CoA thiolase \\
\hline PA1798 & two-component sensor, ParS \\
\hline PA1799 & two-component response regulator, ParR \\
\hline PA1856 & probable cytochrome oxidase subunit \\
\hline PA1930 & probable chemotaxis transducer \\
\hline PA1976 & ErcS' \\
\hline PA1980 & response regulator EraR \\
\hline PA2001 & acetyl-CoA acetyltransferase \\
\hline PA2002 & conserved hypothetical protein \\
\hline PA2018 & $\begin{array}{l}\text { Resistance-Nodulation-Cell Division (RND) multidrug efflux transporter } \\
\text { MexY }\end{array}$ \\
\hline PA2019 & $\begin{array}{l}\text { Resistance-Nodulation-Cell Division (RND) multidrug efflux membrane } \\
\text { fusion protein MexX precursor }\end{array}$ \\
\hline PA2040 & Glutamylpolyamine synthetase \\
\hline PA2051 & transmembrane sensor \\
\hline PA2523 & $\mathrm{CzcR}$ \\
\hline PA2526 & MuxC \\
\hline PA2527 & MuxB \\
\hline PA2528 & MuxA \\
\hline PA2553 & probable acyl-CoA thiolase \\
\hline PA2561 & $\mathrm{CtpH}$ \\
\hline PA2573 & probable chemotaxis transducer \\
\hline PA2583 & probable sensor/response regulator hybrid \\
\hline PA2586 & response regulator GacA \\
\hline PA2652 & methyl-accepting chemotaxis protein \\
\hline PA2654 & TlpQ \\
\hline PA2688 & Ferric enterobactin receptor, outer membrane protein PfeA precursor \\
\hline PA2809 & two-component response regulator, CopR \\
\hline PA2810 & two-component sensor, CopS \\
\hline PA2824 & surface attachment and growth sensor hybrid, SagS \\
\hline PA2920 & probable chemotaxis transducer \\
\hline PA2978 & ptpA; phosphotyrosine protein phosphatase \\
\hline PA3045 & Two-component response regulator, RocA2 \\
\hline PA3345 & Histidine phosphotransfer protein HptB \\
\hline PA3346 & HptB-dependent secretion and biofilm regulator HsbR \\
\hline PA3347 & HptB-dependent secretion and biofilm anti anti-sigma factor HsbA \\
\hline PA3348 & CheR1 \\
\hline PA3349 & probable chemotaxis protein \\
\hline PA3351 & FlgM \\
\hline PA3356 & Glutamylpolyamine synthetase \\
\hline PA3409 & transmembrane sensor \\
\hline PA3471 & probable malic enzyme \\
\hline PA3476 & autoinducer synthesis protein RhlI \\
\hline PA3540 & GDP-mannose 6-dehydrogenase $\mathrm{AlgD}$ \\
\hline PA3552 & ArnB \\
\hline PA3658 & protein-PII uridylyltransferase \\
\hline PA3702 & WspR \\
\hline PA3703 & probable methylesterase \\
\hline PA3704 & probable chemotaxis sensor/effector fusion protein \\
\hline PA3705 & hypothetical protein \\
\hline PA3706 & probable protein methyltransferase \\
\hline PA3707 & hypothetical protein \\
\hline PA3708 & probable chemotaxis transducer \\
\hline PA3714 & probable two-component response regulator \\
\hline PA3872 & respiratory nitrate reductase gamma chain \\
\hline PA3873 & respiratory nitrate reductase delta chain \\
\hline PA3874 & respiratory nitrate reductase beta chain \\
\hline PA3875 & respiratory nitrate reductase alpha chain \\
\hline PA3878 & two-component sensor NarX \\
\hline PA3879 & two-component response regulator NarL \\
\hline PA3900 & transmembrane sensor \\
\hline
\end{tabular}


Table 3 (continued)

\begin{tabular}{|c|c|}
\hline $\begin{array}{l}\text { Locus } \\
\text { Tag }\end{array}$ & Protein name \\
\hline PA3925 & probable acyl-CoA thiolase \\
\hline PA3929 & cyanide insensitive terminal oxidase \\
\hline PA3930 & cyanide insensitive terminal oxidase \\
\hline PA3946 & two-component sensor RocS1 \\
\hline PA3948 & Two-component response regulator RocA1 \\
\hline PA4080 & probable response regulator \\
\hline PA4133 & cytochrome $c$ oxidase subunit (cbb3-type) \\
\hline PA4290 & probable chemotaxis transducer \\
\hline PA4307 & chemotactic transducer PctC \\
\hline PA4309 & chemotactic transducer PctA \\
\hline PA4310 & chemotactic transducer PctB \\
\hline PA4429 & probable cytochrome $c 1$ precursor \\
\hline PA4430 & probable cytochrome $b$ \\
\hline PA4431 & probable iron-sulfur protein \\
\hline PA4462 & RNA polymerase sigma-54 factor \\
\hline PA4493 & RoxR \\
\hline PA4494 & RoxS \\
\hline PA4520 & probable chemotaxis transducer \\
\hline PA4525 & type 4 fimbrial precursor PilA \\
\hline PA4546 & two-component sensor PilS \\
\hline PA4547 & two-component response regulator PilR \\
\hline PA4616 & C4-dicarboxylate-binding protein \\
\hline PA4633 & probable chemotaxis transducer \\
\hline PA4776 & PmrA: two-component regulator system response regulator PmrA \\
\hline PA4777 & PmrB: two-component regulator system signal sensor kinase PmrB \\
\hline PA4785 & probable acyl-CoA thiolase \\
\hline PA4886 & probable two-component sensor \\
\hline PA4915 & probable chemotaxis transducer \\
\hline PA4954 & chemotaxis protein MotA \\
\hline PA4974 & probable outer membrane protein precursor \\
\hline PA5072 & McpK \\
\hline PA5119 & glutamine synthetase \\
\hline PA5124 & two-component sensor NtrB \\
\hline PA5125 & two-component response regulator NtrC \\
\hline PA5165 & DctB \\
\hline PA5166 & DctD \\
\hline PA5167 & DctP \\
\hline PA5168 & DctQ \\
\hline PA5199 & AmgS \\
\hline PA5200 & AmgR \\
\hline PA5261 & alginate biosynthesis regulatory protein $\mathrm{AlgR}$ \\
\hline PA5262 & Fims \\
\hline PA5360 & two-component response regulator $\mathrm{PhoB}$ \\
\hline PA5361 & two-component sensor PhoR \\
\hline PA5369 & $\begin{array}{l}\text { phosphate } \mathrm{ABC} \text { transporter, periplasmic phosphate-binding protein, } \\
\text { PstS }\end{array}$ \\
\hline PA5483 & two-component response regulator $\mathrm{AlgB}$ \\
\hline PA5484 & KinB \\
\hline PA5508 & Glutamylpolyamine synthetase homologue \\
\hline PA5511 & MifR \\
\hline PA5512 & MifS \\
\hline PA5522 & Glutamylpolyamine synthetase \\
\hline
\end{tabular}

\subsubsection{Proteins in two-component signal transduction systems}

Two-component signal transduction systems in $P$. aeruginosa enable the bacteria to sense the environment and respond and adapt its behaviour to better suit prevailing conditions. P. aeruginosa encodes genes for over 60 two-component regulatory systems, being around $10 \%$ of the $P$. aeruginosa genome dedicated to these regulatory networks [61]. These genes encode sensor kinases (SKs) and response regulators (RRs). A total of 212 proteins are annotated in the Two-component System pathway in the KEGG database, being 194 of them (91.5\%) included in Pseudomonas PeptideAtlas. These proteins are listed in Table 3.

\subsubsection{Other proteins with relevance for $P$. aeruginosa infection}

Another group of proteins important for $P$. aeruginosa virulence are the Alp proteins, which constitute a self-lysis pathway that enhances virulence in the host [98]. Only three Alp proteins were identified, two of them unique to samples 15 (AlpA, PA0907) and sample 2 (vesicle and exoproteome; AlpE [PA0911]).

\section{Conclusions}

This work describes the results of analyses of widely diverse $P$. aeruginosa proteomes. The datasets used to build the $P$. aeruginosa PeptideAtlas include the proteomes obtained from strain PAO1 grown under various conditions and from different subcellular fractions (cytosol, membranes, and secretomes). They were analyzed using different proteomic techniques of fractionation, labeling, and MS analysis. It also incorporates datasets from other authors, including one comprising proteins from clinical $P$. aeruginosa strains. All this has allowed the widest coverage of $P$. aeruginosa PAO1 proteins and the highest published coverage by a bacterial PeptideAtlas, higher than those of Leptospira interrogans (65.9\%) [99], Halobacterium salinarum (62.7\%) [100], and Streptococcus pyogenes (55.7\%) [101]. Only 8 PeptideAtlas builds are from bacteria, including 6 derived from pathogens, highlighting the importance of the present work. Quantitative comparative analysis of the level of expression of specific proteins traditionally relies in immunodetection techniques as Western blot or ELISA, amenable to any molecular biology laboratory. However, this is feasible just when the number of proteins to analyze is low and the required antibodies are available. Targeted proteomics is a useful approach when the number of proteins to analyze is large or when the needed antibodies are not available. However, targeted proteomics requires comprehensive information on informative peptides of bacterial proteomes as that provided in the current work. The Atlas here described is hence also a valuable resource for the selection of candidate proteotypic peptides for targeted proteomics experiments via selected reaction monitoring (SRM) or parallel reaction monitoring (PRM).

Supplementary data to this article can be found online at https://doi. org/10.1016/j.jprot.2021.104192.

\section{Credit author statement}

All the authors have contributed significantly to the manuscript.

\section{Declaration of Competing Interest}

None.

\section{Acknowledgements}

This study was supported by RTI2018-094004-B-100 from the Spanish Ministry of Science and Innovation, InGEMICS-CM B2017/ BMD3691 from the Comunidad de Madrid, Spanish Network for Research in Infectious Diseases (REIPI RD16/0016/0011), and PRB3 (PT17/0019/0012) from the ISCIII. InGEMICS-CM, REIPI, and PRB3 are co-financed by the European Development Regional Fund (ERDF) "A way to achieve Europe". These results are lined up with the Human Infectious Diseases HPP initiative from the Human Proteome Project (HID-HPP). The proteomics analyses were performed in the Proteomics facilities of Centro Nacional de Biotecnología (CNB) and Complutense University of Madrid (UCM), both members of the ProteoRed-ISCIII network. This work was funded in part by the National Institutes of Health grants R01GM087221 (EWD/RLM) and R24GM127667(EWD), and by the National Science Foundation grant DBI-1933311 (EWD) and Award Number 1920268 (RLM).

\section{References}

[1] A. Oliver, X. Mulet, C. Lopez-Causape, C. Juan, The increasing threat of Pseudomonas aeruginosa high-risk clones, Drug Resist. Updat. 21-22 (2015) 41-59.

[2] K.S. Kaye, J.M. Pogue, Infections caused by resistant gram-negative bacteria: epidemiology and management, Pharmacotherapy 35 (10) (2015) 949-962.

[3] J.S. Talwalkar, T.S. Murray, The approach to Pseudomonas aeruginosa in cystic fibrosis, Clin. Chest Med. 37 (1) (2016) 69-81. 
[4] L. Martinez-Solano, M.D. Macia, A. Fajardo, A. Oliver, J.L. Martinez, Chronic Pseudomonas aeruginosa infection in chronic obstructive pulmonary disease, Clin. Infect. Dis. 47 (12) (2008) 1526-1533.

[5] J. Eklof, R. Sorensen, T.S. Ingebrigtsen, P. Sivapalan, I. Achir, J.B. Boel, J. Bangsborg, C. Ostergaard, R.B. Dessau, et al., Pseudomonas aeruginosa and risk of death and exacerbations in patients with chronic obstructive pulmonary disease: an observational cohort study of 22053 patients, Clin. Microbiol. Infect. 26 (2) (2019) 227-234

[6] M.F. Moradali, S. Ghods, B.H. Rehm, Pseudomonas aeruginosa lifestyle: a paradigm for adaptation, survival, and persistence, Front. Cell. Infect. Microbiol. 7 (2017) 39.

[7] L. Wiehlmann, G. Wagner, N. Cramer, B. Siebert, P. Gudowius, G. Morales, T. Kohler, C. van Delden, C. Weinel, et al., Population structure of Pseudomonas aeruginosa, Proc. Natl. Acad. Sci. U. S. A. 104 (19) (2007) 8101-8106.

[8] G. Morales, L. Wiehlmann, P. Gudowius, C. van Delden, B. Tummler, J. L. Martinez, F. Rojo, Structure of Pseudomonas aeruginosa populations analyzed by single nucleotide polymorphism and pulsed-field gel electrophoresis genotyping, J. Bacteriol. 186 (13) (2004) 4228-4237.

[9] A. Alonso, F. Rojo, J.L. Martinez, Environmental and clinical isolates of Pseudomonas aeruginosa show pathogenic and biodegradative properties irrespective of their origin, Environ. Microbiol. 1 (5) (1999) 421-430.

[10] J.L. Martinez, Bacterial pathogens: from natural ecosystems to human hosts, Environ. Microbiol. 15 (2) (2013) 325-333.

[11] B. Valot, C. Guyeux, J.Y. Rolland, K. Mazouzi, X. Bertrand, D. Hocquet, What it takes to be a Pseudomonas aeruginosa? The core genome of the opportunistic pathogen updated, PLoS One 10 (5) (2015), e0126468.

[12] S. Mahajan-Miklos, L.G. Rahme, F.M. Ausubel, Elucidating the molecular mechanisms of bacterial virulence using non-mammalian hosts, Mol. Microbiol. 37 (5) (2000) 981-988.

[13] S.P. Diggle, M. Whiteley, Microbe Profile: Pseudomonas aeruginosa: opportunistic pathogen and lab rat, Microbiology (Reading, England) 166 (1) (2020) 30-33.

[14] M.W. Azam, A.U. Khan, Updates on the pathogenicity status of Pseudomonas aeruginosa, Drug Des. Discov. 24 (1) (2019) 350-359.

[15] J. Lee, L. Zhang, The hierarchy quorum sensing network in Pseudomonas aeruginosa, Protein Cell 6 (1) (2015) 26-41.

[16] P. Williams, M. Camara, Quorum sensing and environmental adaptation in Pseudomonas aeruginosa: a tale of regulatory networks and multifunctional signal molecules, Curr. Opin. Microbiol. 12 (2) (2009) 182-191.

[17] A. Sandri, A. Ortombina, F. Boschi, E. Cremonini, M. Boaretti, C. Sorio, P. Melotti, G. Bergamini, M. Lleo, Inhibition of Pseudomonas aeruginosa secreted virulence factors reduces lung inflammation in CF mice, Virulence 9 (1) (2018) 1008-1018.

[18] J.L. Kadurugamuwa, T.J. Beveridge, Natural release of virulence factors in membrane vesicles by Pseudomonas aeruginosa and the effect of aminoglycoside antibiotics on their release, J. Antimicrob. Chemother. 40 (5) (1997) 615-621.

[19] J.L. Kadurugamuwa, T.J. Beveridge, Virulence factors are released from Pseudomonas aeruginosa in association with membrane vesicles during normal growth and exposure to gentamicin: a novel mechanism of enzyme secretion, J. Bacteriol. 177 (14) (1995) 3998-4008.

[20] J. Botelho, F. Grosso, L. Peixe, Antibiotic resistance in Pseudomonas aeruginosa mechanisms, epidemiology and evolution, Drug Resist. Updates. 44 (2019) 100640.

[21] Z. Pang, R. Raudonis, B.R. Glick, T.J. Lin, Z. Cheng, Antibiotic resistance in Pseudomonas aeruginosa: mechanisms and alternative therapeutic strategies, Biotechnol. Adv. 37 (1) (2019) 177-192.

[22] A. Fajardo, N. Martinez-Martin, M. Mercadillo, J.C. Galan, B. Ghysels, S. Matthijs, P. Cornelis, L. Wiehlmann, B. Tummler, F. Baquero, J.L. Martinez, The neglected intrinsic resistome of bacterial pathogens, PLoS One 3 (2) (2008), e1619.

[23] T. Miyoshi-Akiyama, T. Tada, N. Ohmagari, N. Viet Hung, P. Tharavichitkul, B. M. Pokhrel, M. Gniadkowski, M. Shimojima, T. Kirikae, Emergence and spread of epidemic multidrug-resistant Pseudomonas aeruginosa, Genome Biol. Evol. 9 (12) (2017) 3238-3245.

[24] J.A. Reales-Calderon, F. Corona, L. Monteoliva, C. Gil, J.L. Martinez, Quantitative proteomics unravels that the post-transcriptional regulator $\mathrm{Crc}$ modulates the generation of vesicles and secreted virulence determinants of Pseudomonas aeruginosa, J. Proteome 127 (Pt B) (2015) 352-364.

[25] J.F. Linares, R. Moreno, A. Fajardo, L. Martinez-Solano, R. Escalante, F. Rojo, J. L. Martinez, The global regulator Crc modulates metabolism, susceptibility to antibiotics and virulence in Pseudomonas aeruginosa, Environ. Microbiol. 12 (12) (2010) 3196-3212.

[26] E. Sonnleitner, A. Wulf, S. Campagne, X.Y. Pei, M.T. Wolfinger, G. Forlani, K. Prindl, L. Abdou, A. Resch, F.H. Allain, B.F. Luisi, H. Urlaub, U. Blasi, Interplay between the catabolite repression control protein Crc, Hfq and RNA in Hfqdependent translational regulation in Pseudomonas aeruginosa, Nucleic Acids Res. 46 (3) (2018) 1470-1485.

[27] E. Sonnleitner, K. Prindl, U. Blasi, The Pseudomonas aeruginosa CrcZ RNA interferes with Hfq-mediated riboregulation, PLoS One 12 (7) (2017), e0180887.

[28] D.R. Gifford, V. Furio, A. Papkou, T. Vogwill, A. Oliver, R.C. MacLean, Identifying and exploiting genes that potentiate the evolution of antibiotic resistance, Nat. Ecol. Evol. 2 (6) (2018) 1033-1039.

[29] C. Lopez-Causape, L.M. Sommer, G. Cabot, R. Rubio, A.A. Ocampo-Sosa, H. K. Johansen, J. Figuerola, R. Canton, T.J. Kidd, S. Molin, A. Oliver, Evolution of the Pseudomonas aeruginosa mutational resistome in an international cystic fibrosis clone, Sci. Rep. 7 (1) (2017) 5555.

[30] G. Cabot, L. Zamorano, B. Moya, C. Juan, A. Navas, J. Blazquez, A. Oliver, Evolution of Pseudomonas aeruginosa antimicrobial resistance and fitness under low and high mutation rates, Antimicrob. Agents Chemother. 60 (3) (2016) 1767-1778.

[31] F. Sanz-Garcia, C. Alvarez-Ortega, J. Olivares-Pacheco, P. Blanco, J.L. Martinez, S. Hernando-Amado, Analysis of the Pseudomonas aeruginosa aminoglycoside differential resistomes allows defining genes simultaneously involved in intrinsic antibiotic resistance and virulence, Antimicrob. Agents Chemother. 63 (5) (2019).

[32] S. Hernando-Amado, F. Sanz-Garcia, J.L. Martinez, Antibiotic resistance evolution is contingent on the quorum-sensing response in Pseudomonas aeruginosa, Mol. Biol. Evol. 36 (10) (2019) 2238-2251.

[33] F. Sanz-Garcia, S. Hernando-Amado, J.L. Martinez, Mutation-driven evolution of Pseudomonas aeruginosa in the presence of either ceftazidime or ceftazidimeavibactam, Antimicrob. Agents Chemother. 62 (10) (2018).

[34] F. Sanz-Garcia, S. Hernando-Amado, J.L. Martinez, Mutational evolution of Pseudomonas aeruginosa resistance to ribosome-targeting antibiotics, Front. Genet. 9 (2018) 451.

[35] G.L. Winsor, E.J. Griffiths, R. Lo, B.K. Dhillon, J.A. Shay, F.S. Brinkman, Enhanced annotations and features for comparing thousands of Pseudomonas genomes in the Pseudomonas Genome Database, Nucleic Acids Res. 44 (D1) (2016) D646-D653.

[36] W. Huang, L.K. Brewer, J.W. Jones, A.T. Nguyen, A. Marcu, D.S. Wishart, A. G. Oglesby-Sherrouse, M.A. Kane, A. Wilks, PAMDB: a comprehensive Pseudomonas aeruginosa metabolome database, Nucleic Acids Res. 46 (D1) (2018) D575-D580.

[37] C. Gaviard, T. Jouenne, J. Hardouin, Proteomics of Pseudomonas aeruginosa: the increasing role of post-translational modifications, Expert. Rev. Proteomics. 15 (9) (2018) 757-772

[38] M.O. Hesselager, M.C. Codrea, Z. Sun, E.W. Deutsch, T.B. Bennike, A. Stensballe, L. Bundgaard, R.L. Moritz, E. Bendixen, The pig PeptideAtlas: a resource for systems biology in animal production and biomedicine, Proteomics 16 (4) (2016) 634-644.

[39] J.A. Vizcaino, A. Csordas, N. Del-Toro, J.A. Dianes, J. Griss, I. Lavidas, G. Mayer, Y. Perez-Riverol, F. Reisinger, T. Ternent, Q.W. Xu, R. Wang, H. Hermjakob, 2016 update of the PRIDE database and its related tools, Nucleic Acids Res. 44 (22) (2016) 11033

[40] D. Dacheux, J. Goure, J. Chabert, Y. Usson, I. Attree, Pore-forming activity of type III system-secreted proteins leads to oncosis of Pseudomonas aeruginosa-infected macrophages, Mol. Microbiol. 40 (1) (2001) 76-85.

[41] F. Corona, J.A. Reales-Calderon, C. Gil, J.L. Martinez, The development of a new parameter for tracking post-transcriptional regulation allows the detailed map of the Pseudomonas aeruginosa Crc regulon, Sci. Rep. 8 (1) (2018) 16793.

[42] J.A. Vizcaino, R.G. Cote, A. Csordas, J.A. Dianes, A. Fabregat, J.M. Foster, J. Griss, E. Alpi, M. Birim, et al., The Poteomics IDEntifications (PRIDE) database and associated tools: status in 2013, Nucleic Acids Res. 41 (Database issue) (2013) D1063-D1069.

[43] F.A. Herbst, M.T. Sondergaard, H. Kjeldal, A. Stensballe, P.H. Nielsen, M. S. Dueholm, Major proteomic changes associated with amyloid-induced biofilm formation in Pseudomonas aeruginosa PAO1, J. Proteome Res. 14 (1) (2015) 72-81.

[44] A. Penesyan, S.S. Kumar, K. Kamath, A.M. Shathili, V. Venkatakrishnan, C. Krisp, N.H. Packer, M.P. Molloy, I.T. Paulsen, Genetically and phenotypically distinct Pseudomonas aeruginosa cystic fibrosis isolates share a core proteomic signature, PLoS One 10 (10) (2015), e0138527.

[45] M.G. Casabona, Y. Vandenbrouck, I. Attree, Y. Coute, Proteomic characterization of Pseudomonas aeruginosa PAO1 inner membrane, Proteomics 13 (16) (2013) 2419-2423.

[46] M. Robert-Genthon, M.G. Casabona, D. Neves, Y. Coute, F. Ciceron, S. Elsen, A. Dessen, I. Attree, Unique features of a Pseudomonas aeruginosa alpha2macroglobulin homolog, mBio 4 (4) (2013).

[47] L. Martens, M. Chambers, M. Sturm, D. Kessner, F. Levander, J. Shofstahl, W. H. Tang, A. Rompp, S. Neumann, et al., mzML-a community standard for mass spectrometry data, Mol. Cell. Proteomics:. 10 (1) (2011). R110.000133.

[48] J.K. Eng, T.A. Jahan, M.R. Hoopmann, Comet: an open-source MS/MS sequence database search tool, Proteomics 13 (1) (2013) 22-24.

[49] J.K. Eng, A.L. McCormack, J.R. Yates, An approach to correlate tandem mass spectral data of peptides with amino acid sequences in a protein database, J. Am. Soc. Mass Spectrom. 5 (11) (1994) 976-989.

[50] R. Craig, R.C. Beavis, TANDEM: matching proteins with tandem mass spectra, Bioinformatics (Oxford, England) 20 (9) (2004) 1466-1467.

[51] B. MacLean, J.K. Eng, R.C. Beavis, M. McIntosh, General framework for developing and evaluating database scoring algorithms using the TANDEM search engine, Bioinformatics 22 (22) (2006) 2830-2832.

[52] L.Y. Geer, S.P. Markey, J.A. Kowalak, L. Wagner, M. Xu, D.M. Maynard, X. Yang, W. Shi, S.H. Bryant, Open mass spectrometry search algorithm, J. Proteome Res. 3 (5) (2004) 958-964.

[53] E.W. Deutsch, L. Mendoza, D. Shteynberg, J. Slagel, Z. Sun, R.L. Moritz, Transproteomic pipeline, a standardized data processing pipeline for large-scale reproducible proteomics informatics, Proteomics Clin. Appl. 9 (7-8) (2015) 745-754.

[54] E.W. Deutsch, L. Mendoza, D. Shteynberg, T. Farrah, H. Lam, N. Tasman, Z. Sun, E. Nilsson, B. Pratt, B. Prazen, J.K. Eng, D.B. Martin, A.I. Nesvizhskii, R. Aebersold, A guided tour of the trans-proteomic pipeline, Proteomics 10 (6) (2010) 1150-1159.

[55] A. Keller, A.I. Nesvizhskii, E. Kolker, R. Aebersold, Empirical statistical model to estimate the accuracy of peptide identifications made by MS/MS and database search, Anal. Chem. 74 (20) (2002) 5383-5392. 
[56] D. Shteynberg, E.W. Deutsch, H. Lam, J.K. Eng, Z. Sun, N. Tasman, L. Mendoza, R. L. Moritz, R. Aebersold, A.I. Nesvizhskii, iProphet: multi-level integrative analysis of shotgun proteomic data improves peptide and protein identification rates and error estimates, Mol. Cell. Proteomics:. 10 (12) (2011). M111.007690.

[57] A.I. Nesvizhskii, A. Keller, E. Kolker, R. Aebersold, A statistical model for identifying proteins by tandem mass spectrometry, Anal. Chem. 75 (17) (2003) 4646-4658.

[58] L. Reiter, M. Claassen, S.P. Schrimpf, M. Jovanovic, A. Schmidt, J.M. Buhmann, M.O. Hengartner, R. Aebersold, Protein identification false discovery rates for very large proteomics data sets generated by tandem mass spectrometry, Mol. Cell. Proteomics:. 8 (11) (2009) 2405-2417.

[59] M. Kanehisa, Y. Sato, KEGG mapper for inferring cellular functions from protein sequences, Protein Sci. 29 (1) (2019) 28-35.

[60] M. Kanehisa, M. Furumichi, M. Tanabe, Y. Sato, K. Morishima, KEGG: new perspectives on genomes, pathways, diseases and drugs, Nucleic Acids Res. 45 (D1) (2017) D353-D361.

[61] C.K. Stover, X.Q. Pham, A.L. Erwin, S.D. Mizoguchi, P. Warrener, M.J. Hickey, F. S.L. Brinkman, W.O. Hufnagle, D.J. Kowalik, et al., Complete genome sequence of Pseudomonas aeruginosa PAO1, an opportunistic pathogen, Nature 406 (6799) (2000) 959-964.

[62] M. Schobert, D. Jahn, Anaerobic physiology of Pseudomonas aeruginosa in the cystic fibrosis lung, Int. J. Med. Microbiol. 300 (8) (2010) 549-556.

[63] J. Walker, G. Moore, Pseudomonas aeruginosa in hospital water systems: biofilms, guidelines, and practicalities, J. Hosp. Infect. 89 (4) (2015) 324-327.

[64] J.F. Linares, I. Gustafsson, F. Baquero, J.L. Martinez, Antibiotics as intermicrobial signaling agents instead of weapons, Proc. Natl. Acad. Sci. U. S. A. 103 (51) (2006) 19484-19489.

[65] Y. Zhang, Z. Lin, P. Hao, K. Hou, Y. Sui, K. Zhang, Y. He, H. Li, H. Yang, S. Liu, Y. Ren, Improvement of peptide separation for exploring the missing proteins localized on membranes, J. Proteome Res. 17 (12) (2018) 4152-4159.

[66] T. Beaudoin, L. Zhang, A.J. Hinz, C.J. Parr, T.F. Mah, The biofilm-specific antibiotic resistance gene ndvB is important for expression of ethanol oxidation genes in Pseudomonas aeruginosa biofilms, J. Bacteriol. 194 (12) (2012) 3128-3136.

[67] M. Zhu, J. Zhao, H. Kang, W. Kong, Y. Zhao, M. Wu, H. Liang, Modulation of type III secretion system in Pseudomonas aeruginosa: involvement of the PA4857 gene product, Front. Microbiol. 7 (2016).

[68] M. Zhu, J. Zhao, H. Kang, W. Kong, Y. Zhao, M. Wu, H. Liang, Corrigendum: modulation of Type III secretion system in Pseudomonas aeruginosa: involvement of the PA4857 gene product, Front. Microbiol. 7 (2016).

[69] E.E. Smith, D.G. Buckley, Z. Wu, C. Saenphimmachak, L.R. Hoffman, D. A. D’Argenio, S.I. Miller, B.W. Ramsey, D.P. Speert, S.M. Moskowitz, J.L. Burns, R. Kaul, M.V. Olson, Genetic adaptation by Pseudomonas aeruginosa to the airways of cystic fibrosis patients, Proc. Natl. Acad. Sci. U. S. A. 103 (22) (2006) 8487-8492.

[70] K.M. Colvin, Y. Irie, C.S. Tart, R. Urbano, J.C. Whitney, C. Ryder, P.L. Howell, D. J. Wozniak, M.R. Parsek, The Pel and Psl polysaccharides provide Pseudomonas aeruginosa structural redundancy within the biofilm matrix, Environ. Microbiol. 14 (8) (2012) 1913-1928.

[71] L.R. Hoffman, D.A. D’Argenio, M.J. MacCoss, Z. Zhang, R.A. Jones, S.I. Miller, Aminoglycoside antibiotics induce bacterial biofilm formation, Nature 436 (7054) (2005) 1171-1175.

[72] N. Pakharukova, M. Tuittila, S. Paavilainen, H. Malmi, O. Parilova, S. Teneberg, S.D. Knight, A.V. Zavialov, Structural basis for Acinetobacter baumannii biofilm formation, Proc. Natl. Acad. Sci. U. S. A. 115 (21) (2018) 5558-5563.

[73] B.R. Borlee, A.D. Goldman, K. Murakami, R. Samudrala, D.J. Wozniak, M. R. Parsek, Pseudomonas aeruginosa uses a cyclic-di-GMP-regulated adhesin to reinforce the biofilm extracellular matrix, MolMicrobiol 75 (4) (2010) 827-842.

[74] A. Balyimez, J.A. Colmer-Hamood, M. San Francisco, A.N. Hamood, Characterization of the Pseudomonas aeruginosa metalloendopeptidase, Mep72, a member of the Vfr regulon, BMC Microbiol. 13 (2013) 269.

[75] I.J. Passmore, K. Nishikawa, K.S. Lilley, S.D. Bowden, J.C. Chung, M. Welch, Mep72, a metzincin protease that is preferentially secreted by biofilms of Pseudomonas aeruginosa, J. Bacteriol. 197 (4) (2015) 762-773.

[76] J.C. Chung, O. Rzhepishevska, M. Ramstedt, M. Welch, Type III secretion system expression in oxygen-limited Pseudomonas aeruginosa cultures is stimulated by isocitrate lyase activity, Open Biol. 3 (1) (2013) 120131.

[77] G.H. Kaihami, L.C.D. Breda, J.R.F. de Almeida, T. de Oliveira Pereira, G. G. Nicastro, A.L. Boechat, S.R. de Almeida, R.L. Baldini, The atypical response regulator atvr is a new player in Pseudomonas aeruginosa response to hypoxia and virulence, Infect. Immun. 85 (8) (2017).

[78] G.I. Lucchesi, T.A. Lisa, C.H. Casale, C.E. Domenech, Carnitine resembles choline in the induction of cholinesterase, acid phosphatase, and phospholipase C and in its action as an osmoprotectant in Pseudomonas aeruginosa, Curr. Microbiol. 30 (1) (1995) 55-60.

[79] J.A. Meadows, M.J. Wargo, Characterization of Pseudomonas aeruginosa growth on O-acylcarnitines and identification of a short-chain acylcarnitine hydrolase, Appl. Environ. Microbiol. 79 (11) (2013) 3355-3363.
[80] K. Koeppen, R. Barnaby, A.A. Jackson, S.A. Gerber, D.A. Hogan, B.A. Stanton, Tobramycin reduces key virulence determinants in the proteome of Pseudomonas aeruginosa outer membrane vesicles, PLoS One 14 (1) (2019), e0211290.

[81] P. Tielen, H. Kuhn, F. Rosenau, K.E. Jaeger, H.C. Flemming, J. Wingender, Interaction between extracellular lipase LipA and the polysaccharide alginate of Pseudomonas aeruginosa, BMC Microbiol. 13 (2013) 159.

[82] Y. Jin, H. Yang, M. Qiao, S. Jin, MexT regulates the type III secretion system through MexS and PtrC in Pseudomonas aeruginosa, J. Bacteriol. 193 (2) (2011) 399-410.

[83] T. Kohler, S.F. Epp, L.K. Curty, J.C. Pechere, Characterization of MexT, the regulator of the MexE-MexF-OprN multidrug efflux system of Pseudomonas aeruginosa, J. Bacteriol. 181 (20) (1999) 6300-6305.

[84] S.K. Arora, B.W. Ritchings, E.C. Almira, S. Lory, R. Ramphal, A transcriptional activator, FleQ, regulates mucin adhesion and flagellar gene expression in Pseudomonas aeruginosa in a cascade manner, J. Bacteriol. 179 (17) (1997) 5574-5581.

[85] J.D. Mougous, M.E. Cuff, S. Raunser, A. Shen, M. Zhou, C.A. Gifford, A. L. Goodman, G. Joachimiak, C.L. Ordonez, et al., A virulence locus of Pseudomonas aeruginosa encodes a protein secretion apparatus, Science 312 (5779) (2006) 1526-1530.

[86] A. Hachani, N.S. Lossi, A. Hamilton, C. Jones, S. Bleves, D. Albesa-Jove, A. Filloux, Type VI secretion system in Pseudomonas aeruginosa: secretion and multimerization of VgrG proteins, J. Biol. Chem. 286 (14) (2011) 12317-12327.

[87] F. Corona, P. Blanco, M. Alcalde-Rico, S. Hernando-Amado, F. Lira, A. Bernardini, M.B. Sanchez, J.L. Martinez, The analysis of the antibiotic resistome offers new opportunities for therapeutic intervention, Future Med. Chem. 8 (10) (2016) 1133-1151.

[88] A. Daddaoua, C. Molina-Santiago, J. de la Torre, T. Krell, J.L. Ramos, GtrS and GltR form a two-component system: the central role of 2-ketogluconate in the expression of exotoxin a and glucose catabolic enzymes in Pseudomonas aeruginosa, Nucleic Acids Res. 42 (12) (2014) 7654-7663.

[89] K.F. Kong, S.R. Jayawardena, S.D. Indulkar, A. Del Puerto, C.L. Koh, N. Hoiby, K. Mathee, Pseudomonas aeruginosa AmpR is a global transcriptional factor that regulates expression of AmpC and PoxB beta-lactamases, proteases, quorum sensing, and other virulence factors, Antimicrob. Agents Chemother. 49 (11) (2005) 4567-4575.

[90] G. Dieppois, V. Ducret, O. Caille, K. Perron, The transcriptional regulator CzcR modulates antibiotic resistance and quorum sensing in Pseudomonas aeruginosa, PLoS One 7 (5) (2012), e38148.

[91] K.N. Raymond, E.A. Dertz, S.S. Kim, Enterobactin: an archetype for microbial iron transport, Proc. Nat. Acad. Sci. USA. 100 (7) (2003) 3584-3588.

[92] S. Chevalier, E. Bouffartigues, A. Bazire, A. Tahrioui, R. Duchesne, D. Tortuel, O. Maillot, T. Clamens, N. Orange, et al., Extracytoplasmic function sigma factors in Pseudomonas aeruginosa, Biochim. Biophys. Acta Gene. Regul. Mech. 1862 (7) (2019) 706-721.

[93] M. Hannauer, A. Braud, F. Hoegy, P. Ronot, A. Boos, I.J. Schalk, The PvdRTOpmQ efflux pump controls the metal selectivity of the iron uptake pathway mediated by the siderophore pyoverdine in Pseudomonas aeruginosa, Environ. Microbiol. 14 (7) (2012) 1696-1708.

[94] S. Elias, E. Degtyar, E. Banin, FvbA is required for vibriobactin utilization in Pseudomonas aeruginosa, Microbiology 157 (Pt 7) (2011) 2172-2180.

[95] M.A. Llamas, M. Sparrius, R. Kloet, C.R. Jimenez, C. Vandenbroucke-Grauls, W. Bitter, The heterologous siderophores ferrioxamine B and ferrichrome activate signaling pathways in Pseudomonas aeruginosa, J. Bacteriol. 188 (5) (2006) 1882-1891.

[96] K.C. Bastiaansen, P. van Ulsen, M. Wijtmans, W. Bitter, M.A. Llamas, Selfcleavage of the Pseudomonas aeruginosa cell-surface signaling anti-sigma factor FoxR occurs through an N-O acyl rearrangement, J. Biol. Chem. 290 (19) (2015) 12237-12246.

[97] R. Wegele, R. Tasler, Y. Zeng, M. Rivera, N. Frankenberg-Dinkel, The heme oxygenase(s)-phytochrome system of Pseudomonas aeruginosa, J. Biol. Chem. 279 (44) (2004) 45791-45802.

[98] K.A. McFarland, E.L. Dolben, M. LeRoux, T.K. Kambara, K.M. Ramsey, R. L. Kirkpatrick, J.D. Mougous, D.A. Hogan, S.L. Dove, A self-lysis pathway that enhances the virulence of a pathogenic bacterium, Proc. Natl. Acad. Sci. U. S. A. 112 (27) (2015) 8433-8438.

[99] J. Malmstrom, M. Beck, A. Schmidt, V. Lange, E.W. Deutsch, R. Aebersold, Proteome-wide cellular protein concentrations of the human pathogen Leptospira interrogans, Nature 460 (7256) (2009) 762-765.

[100] P.T. Van, A.K. Schmid, N.L. King, A. Kaur, M. Pan, K. Whitehead, T. Koide, M. T. Facciotti, Y.A. Goo, et al., Halobacterium salinarum NRC-1 PeptideAtlas: toward strategies for targeted proteomics and improved proteome coverage, J. Proteome Res. 7 (9) (2008) 3755-3764.

[101] V. Lange, J.A. Malmstrom, J. Didion, N.L. King, B.P. Johansson, J. Schafer, J. Rameseder, C.H. Wong, E.W. Deutsch, et al., Targeted quantitative analysis of Streptococcus pyogenes virulence factors by multiple reaction monitoring, Mol. Cell. Proteomics:. 7 (8) (2008) 1489-1500. 